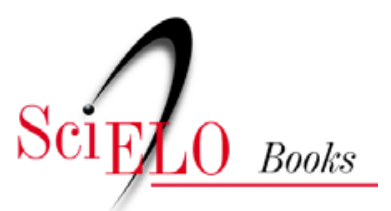

\title{
5 - Dinâmica dos investimentos no subsistema de serviços de saúde
}

Carlos A. Grabois Gadelha (cood.)

\section{SciELO Books / SciELO Livros / SciELO Libros}

GADELHA, CAG., cood. Dinâmica dos investimentos no subsistema de serviços de saúde. In: A dinâmica do sistema produtivo da saúde: inovação e complexo econômico-industrial [online]. Rio de Janeiro: Editora FIOCRUZ, 2012, pp. 143-175. ISBN: 978-85-7541-593-1. Available from: doi: 10.7476/9788575415931.0006. Also available in ePUB from: http://books.scielo.org/id/6t3hs/epub/gadelha-9788575415931.epub

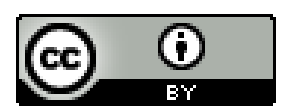

All the contents of this work, except where otherwise noted, is licensed under a Creative Commons Attribution $\underline{4.0 \text { International license. }}$

Todo o conteúdo deste trabalho, exceto quando houver ressalva, é publicado sob a licença Creative Commons Atribição 4.0. 


\section{5}

\section{Dinâmica dos Investimentos no Subsistema de Serviços de Saúde}

Com base no conceito de Complexo Econômico-Industrial da Saúde (CEIS), é possível compreender o segmento dos serviços como importante força motriz da interação e interdependência da dinâmica da base produtiva da saúde, cujo caráter sistêmico é conferido pela atividade econômica. Os serviços de saúde constituem segmento de maior peso econômico do sistema; apresentam importante capacidade intrínseca tanto de gerar renda e emprego quanto de constituir o mercado final dos outros segmentos do complexo produtivo da saúde, além de participarem decisivamente - se bem que de forma ainda pouco trabalhada - na dinâmica sistêmica de inovação.

No que diz respeito ao setor mais especificamente sanitário, o segmento de serviços encontra-se configurado sob a forma de sistemas de saúde em boa parte dos países desenvolvidos, para fazer frente à diversidade de demandas por maior eficiência e eficácia. Requer articulação sistêmica, sob a forma de rede de serviços estruturada em torno de princípios diversos, entre os quais se destaca a concepção de níveis de complexidade tecnológica e escala econômica, que permita responder às diferentes demandas assistenciais. ${ }^{26}$

Nessa configuração dos serviços de atenção à saúde, há significativa diversidade de portes organizacionais, variadas funções assistenciais e distintas complexidades tecnológicas. Variando conforme políticas e tipos organizacionais, em boa parte dos países tal configuração abrange desde postos de saúde ou unidades assistenciais ambulatoriais, consultórios médicos e outros serviços simplificados de saúde até complexos hospitalares multiespecializados, passando por toda uma gama de serviços de complexidade intermediária, tanto de assistência direta à população quanto

\footnotetext{
${ }^{26}$ Para uma abordagem atualizada das políticas e sistemas de saúde, ver a coletânea recentemente organizada por Giovanella e colaboradores (2008), que abrange conceitualmente as dimensões de proteção social e econômica e desenvolve uma análise histórica da experiência brasileira.
} 
de suporte diagnóstico-terapêutico e ainda de serviços paramédicos. No âmbito do complexo, esses serviços são responsáveis por grande parte do seu dinamismo econômico, com destaque para o papel dos hospitais e centros de diagnóstico e terapia mais complexos, dada sua condição de produtores especializados de serviços e igualmente demandadores e indutores de novas e diferenciadas tecnologias.

$\mathrm{Na}$ condição de concentradores e demandantes das mais complexas tecnologias, os referidos serviços são responsáveis por parte extremamente importante do consumo de equipamentos médico-hospitalares, materiais médico-cirúrgicos, medicamentos, imunobiológicos e outros insumos e produtos em saúde em um país, por toda uma gama de serviços de Tecnologia de Informação (TI), além de insumos de natureza administrativa e logística. No concernente à inovação em saúde, seu papel é marcante no campo da prática médica, compreendida como a implementação de novas tecnologias de atenção, boa parte delas possível em decorrência de inovações geradas por outros agentes, fundamentalmente oriundas do segmento de produção de bens industriais. Os hospitais, no entanto, especialmente os mais complexos e especializados, e as empresas voltadas para diagnósticos médicos são mais do que meros produtores de serviços. Sua maior diferenciação permite importantes interações com outros agentes do complexo, com pesos mais importantes em inovações no segmento de produtos médicos e sanitários em geral.

O Subsistema de Serviços em Saúde experimenta importantes transformações, decorrentes de pelo menos três grandes vetores intercondicionados: a própria dinâmica de inovação do complexo produtivo da saúde, que gera novas possibilidades nos serviços, alterando, sobretudo, suas formas organizativas, seus processos, produtos e mercados, incluindo suas escalas ou escopos; a própria dinâmica demográfica e epidemiológica das populações, que configura por si e permanentemente novas necessidades, demandas e mercados; e a ação dos governos, por meio de políticas públicas que cada vez mais modulam a sua dinâmica de crescimento, em função da natureza social e da responsabilidade crescente do Estado nesse espaço social.

Antes de apresentar dados e informações de dimensão econômica restrita, é preciso considerar alguns condicionamentos de natureza sociossanitária que, por sua significativa influência sobre as estruturas e o funcionamento dos serviços de saúde, exercem impacto decisivo sobre a dinâmica de mercado tanto do subsistema quanto do CEIS como um todo. A Figura 5 apresenta, sinteticamente, um conjunto de categorias e dimensões que impactam a estrutura, a utilização, o desempenho e o desenvolvimento dos serviços. É importante reiterar que os aspectos demográficos e epidemiológicos mencionados anteriormente e referentes à política e organização dos sistemas nacionais de saúde - sistemas mais ou menos universais, formas de financiamento, modelos assistenciais etc. - são importantes vetores que condicionam a estrutura e o desempenho dos serviços. E que, claramente, a interpenetração entre elementos políticos, institucionais, sociais e econômicos determina a direção das trajetórias nacionais de inovação e a dinâmica global e nacional dos investimentos. 
Figura 5 - Elementos condicionantes dos serviços de saúde

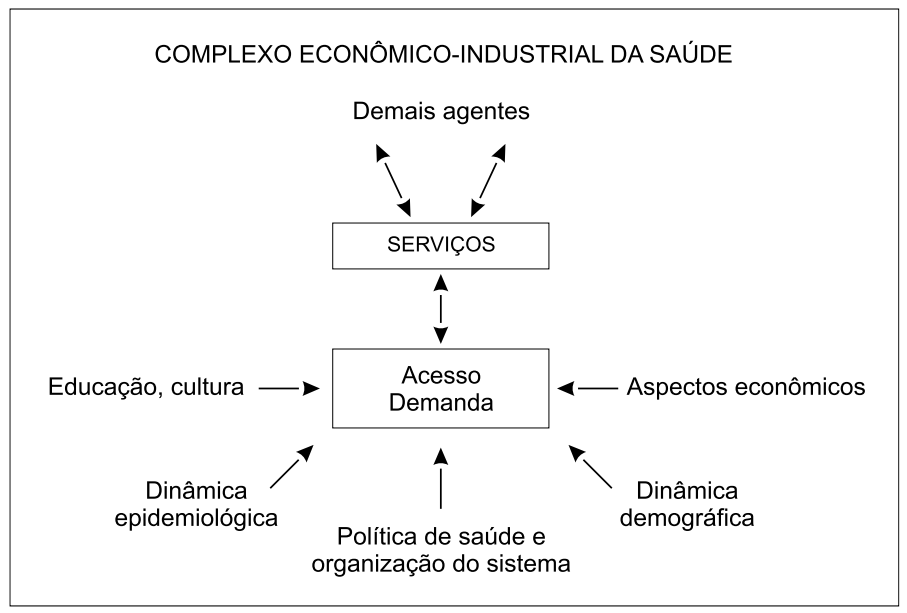

Fonte: elaborado por GIS/Ensp-VPPIS/Fiocruz, 2008.

\section{DINÂMICA GLOBAL DE INVESTIMENTOS}

A inserção do segmento de serviços de saúde no mercado internacional tem condicionantes específicos. Não de trata de uma área de mercado em que a competição global ocorre na mesma intensidade dos subsistemas industriais de Fármacos e Medicamentos e de Equipamentos Médico-Hospitalares, apesar de as transformações em curso apontarem, crescentemente, para uma lógica global de investimento. Os serviços apresentam dinâmicas próprias e em geral menos expressivas quanto à internacionalização e à disputa global de mercados, ainda que se observem, em particular no âmbito da prestação de serviços de diagnóstico médico, movimentos e tendências em direção à conquista de mercados externos por parte de firmas de alguns países centrais e mesmo em âmbito regional.

Neste capítulo ganha, portanto, mais importância o conhecimento da dinâmica interna de investimentos nos serviços, muito embora sejam apresentadas informações importantes para os movimentos globais, sobretudo na atenção hospitalar, como segmento produtivo privilegiado deste subsistema.

Ao longo das duas últimas décadas, os sistemas nacionais de saúde têm sido objeto de profundas e sucessivas transformações nas suas orientações políticas, nos padrões de financiamento e nos princípios e diretrizes relativos à organização da rede de serviços e ao modelo de atenção à saúde até então adotado (Saltman, Figueras \& Sakerllarides, 1998; Mendes, 2001; McKee \& Healy, 2002).

Não obstante todas as mudanças nos sistemas de saúde e os questionamentos daí advindos sobre o papel da assistência hospitalar na atenção à saúde, os hospitais continuam exercendo um papel-chave na prestação de cuidados de saúde, por 
continuarem concentrando os saberes e as tecnologias mais especializados e porque os gastos hospitalares representam, em média, cerca de metade dos gastos nacionais em saúde (McKee \& Healy, 2000).

Ao mesmo tempo, no contexto de reformas dos sistemas de saúde, são notórias as mudanças pelas quais os hospitais têm passado. Essas mudanças compreendem não só a redefinição do papel da assistência hospitalar nos sistemas de atenção à saúde, mas também a reorganização interna desses estabelecimentos. No âmbito assistencial, mediante a incorporação de novas tecnologias e a adequação do espaço físico interno, observam-se a implantação e a difusão de novas formas de prestação de cuidados por exemplo, a cirurgia ambulatorial e o hospital-dia. Na esfera administrativa, as preocupações com o uso mais eficiente dos recursos disponíveis têm se traduzido em um forte movimento em prol da profissionalização da gestão desses estabelecimentos, acompanhado pela adoção de novas técnicas e ferramentas gerenciais e de modernos sistemas de informação.

É incontestável que os hospitais continuam desempenhando um papel extremamente importante na prestação de cuidados de saúde. O momento atual tem sido fortemente marcado pela introdução de diversas inovações nessas instituições, seja no escopo das atividades ali ofertadas, seja no que tange à sua maior integração à rede de serviços, seja, ainda, na forma de geri-los, com a emergência de novos modelos de gestão hospitalar (Opas, 2004).

o processo de expansão dos sistemas nacionais de saúde no período do pósguerra, mediante políticas de extensão do acesso e de ampliação da cesta de serviços oferecidos à população, vem acompanhado de um crescimento em espiral dos custos da assistência. Os gastos em saúde nos países desenvolvidos durante os anos 60-70 do último século evoluíram com taxas médias de crescimento anual acima das taxas de crescimento anual das economias nacionais. Ou seja, ao longo do referido período esses gastos passaram a consumir parcelas crescentes do Produto Interno Bruto (PIB) desses países.

No fim dos anos 1970, o contexto econômico mais adverso provocou uma desaceleração dos gastos em saúde, sob pena de o financiamento da saúde se tornar socialmente insustentável. Redirecionadas, as políticas de saúde de vários governos passaram a se pautar pela contenção de gastos e pela busca de maior eficiência e qualidade nos seus resultados. E, uma vez que os hospitais se encontram no centro do modelo de atenção e consomem a maior parcela dos recursos setoriais, foi sobre esse segmento assistencial que grande parte das medidas então adotadas procurou incidir.

Várias políticas e ações de reforma, nas últimas décadas do século XX, no âmbito da assistência médico-hospitalar e do funcionamento e gestão dos hospitais, tiveram suas raízes em duas grandes vertentes. A primeira, associada à preocupação, de ordem econômica, com o controle dos gastos sanitários, foi a implementação de medidas de racionalização da oferta de serviços e de modernização da gestão dos serviços 
de saúde, sobretudo os hospitais. A segunda, articulada à formulação de um novo modelo de organização do cuidado à saúde, fundava-se em uma concepção de sistema integrado de serviços de saúde segundo a qual a atenção básica, e não a assistência hospitalar, deveria ser o centro do sistema.

Os avanços científicos e tecnológicos alcançados permitiram que parte dos procedimentos então realizados exclusivamente no interior do hospital fossem gradativamente deslocados para outros ambientes. Houve uma desconcentração da prestação de diversos serviços assistenciais e, assim, surgiram novas modalidades assistenciais - caso do hospital-dia, da cirurgia ambulatorial, da assistência domiciliar ou mesmo de novos tipos de serviços de saúde, como os dos centros de enfermagem (nursing homes) (Shortell, Gillies \& Devers, 1995).

Na vigência desse novo padrão de utilização dos leitos hospitalares, a capacidade instalada de leitos logo se revelou excessiva. Assim, em tal cenário, ao longo dos últimos vinte anos diferentes países procuraram colocar em prática políticas voltadas para a racionalização da oferta hospitalar ou, em outras palavras, para a chamada política de desospitalização, mediante estratégias variadas que envolviam a redução de leitos hospitalares, o fechamento ou a fusão de hospitais, a conversão de estabelecimentos hospitalares em casas de enfermagem etc.

As evidências relativas ao processo em curso não dão margem a dúvidas: acompanhando a organização de um novo modelo de atenção à saúde, a assistência hospitalar e os estabelecimentos hospitalares passaram por fase de transformações radicais. Encontra-se em gestação um novo hospital, que agora opera integrado a uma rede diversificada de serviços de saúde. Esse novo hospital, necessariamente de maior densidade tecnológica, tem um domínio de ação mais restrito, voltado especificamente para o atendimento dos casos mais graves, que exigem cuidados intensivos. Ao mesmo tempo, aumentam as suas responsabilidades como serviço de retaguarda e de apoio técnico à rede assistencial, como instituição de formação de especialistas e de desenvolvimento da educação permanente e ainda como espaço de desenvolvimento de projetos de investigação clínica, epidemiológica e administrativa. A instituição hospitalar mais uma vez se renova e segue exercendo um papel importante no sistema de saúde.

A Tabela 30 apresenta alguns dados que ressaltam a importância da atenção hospitalar na despesa global em saúde, evidenciando o peso do setor tanto no CEIS quanto no Subsistema de Serviços. Destaca-se a elevada concentração de leitos por habitantes - em comparação com o Brasil -, muito embora em quase todos os países outros dados nos informem clara tendência de fechamento de hospitais e leitos.

Observa-se nítida e mesmo espetacular queda no número de leitos (Gráfico 25) desde os anos 80 e redução na taxa de internação, sobretudo a partir da segunda metade da década de 90 (Gráfico 26). Ambas são decorrência de novas tecnologias extra-hospitalares, que geram mais eficiência e eficácia para tratamentos fora do 
hospital (destaque para cirurgias ambulatoriais e internações domiciliares), assim como da maior importância conferida à atenção básica a partir de unidades não hospitalares, sejam centros de saúde, ambulatórios, clínicas, consultórios ou outros equipamentos sanitários. Igualmente ganham peso os desenvolvimentos tecnológicos intra-hospitalares, mediante incorporações tecnológicas de equipamentos e novos fármacos e medicamentos, que condicionam reduções significativas nos tempos de internação (Gráfico 27) e, portanto, na intensidade do uso de leitos nas práticas assistenciais quando vistas em suas diversas modalidades. Não se pode afirmar que se trata apenas de fruto de maior taxa de utilização dos leitos disponíveis, pois este indicador não apresenta uma nítida tendência no âmbito de países desenvolvidos selecionados (Gráfico 28).

Tabela 30 - Gastos em saúde, alguns indicadores hospitalares e de equipamentos pesados em países selecionados da União Europeia - 2008

\begin{tabular}{|c|c|c|c|c|c|c|c|c|c|}
\hline \multirow{2}{*}{ CARACTERÍSTICA } & \multicolumn{9}{|c|}{ PAÍS } \\
\hline & ALEMANHA & ÁUSTRIA & BÉLGICA & ESPANHA & FRANÇA & ITÁLIA & HOLANDA & POLÔNIA & $\begin{array}{l}\text { REINO } \\
\text { UNIDO }\end{array}$ \\
\hline \% saúde PIB & $10,9 \%$ & $9,6 \%$ & $9,9 \%$ & $8,1 \%$ & $10,5 \%$ & $8,7 \%$ & $8,9 \%$ & $6,5 \%$ & $8,3 \%$ \\
\hline $\begin{array}{l}\text { \% financiamento } \\
\text { público }\end{array}$ & $78,1 \%$ & $67,6 \%$ & $70,9 \%$ & $71,9 \%$ & $76,5 \%$ & $76,4 \%$ & $61,2 \%$ & $70,0 \%$ & $85,9 \%$ \\
\hline Leitos públicos & $74,7 \%$ & $76,2 \%$ & $35,5 \%$ & $66,2 \%$ & $65,5 \%$ & $77,0 \%$ & $15,5 \%$ & $96,3 \%$ & nd \\
\hline Leitos/mil habitantes & 6,5 & 6,0 & 4,8 & 2,7 & 3,7 & 3,5 & 3,1 & 4,7 & nd \\
\hline $\begin{array}{l}\text { \% despesas } \\
\text { hospitalares } \\
\text { (total Saúde) }\end{array}$ & $34,7 \%$ & $41,7 \%$ & $34,8 \%$ & $25,9 \%$ & $33,8 \%$ & $44,1 \%$ & $39,6 \%$ & $28,1 \%$ & nd \\
\hline \multirow{3}{*}{$\begin{array}{l}\text { Equipamentos por } \\
\text { milhão de habitantes }\end{array}$} & RM 6,6 & 14,9 & 6,8 & 7,7 & 3,2 & 10,2 & nd & 1,0 & 5,0 \\
\hline & Radio 4,7 & 4,6 & 6,8 & 3,9 & 6,0 & 4,1 & nd & nd & 3,9 \\
\hline & TC 15,4 & 28,5 & 29,8 & 13,3 & 7,5 & 20,6 & nd & 6,3 & 7,0 \\
\hline
\end{tabular}

nd - não disponível; RM - ressonância magnética; Radio - radioterapia; TC - tomografia computadorizada.

Fonte: Les Hôpitaux..., 2008.

Equipamentos no Brasil (AMS/IBGE, 2006):

RM - Total: 549 (2,9/milhão); disponíveis SUS país: 175 (0,9/milhão); disponíveis SUS região SE: 74;

Rádio - Total: 604 (3,3/milhão); disponíveis SUS país: 401(2,2/milhão); disponíveis SUS região SE: 321;

TC - Total: 1.961(10,6/milhão); disponíveis SUS país: 858 (4,6/milhão); disponíveis SUS região SE: 436. 
Gráfico 25 - Leitos hospitalares em países selecionados da Europa e no conjunto da União Europeia (por 100.000 habitantes) - 1970-2009

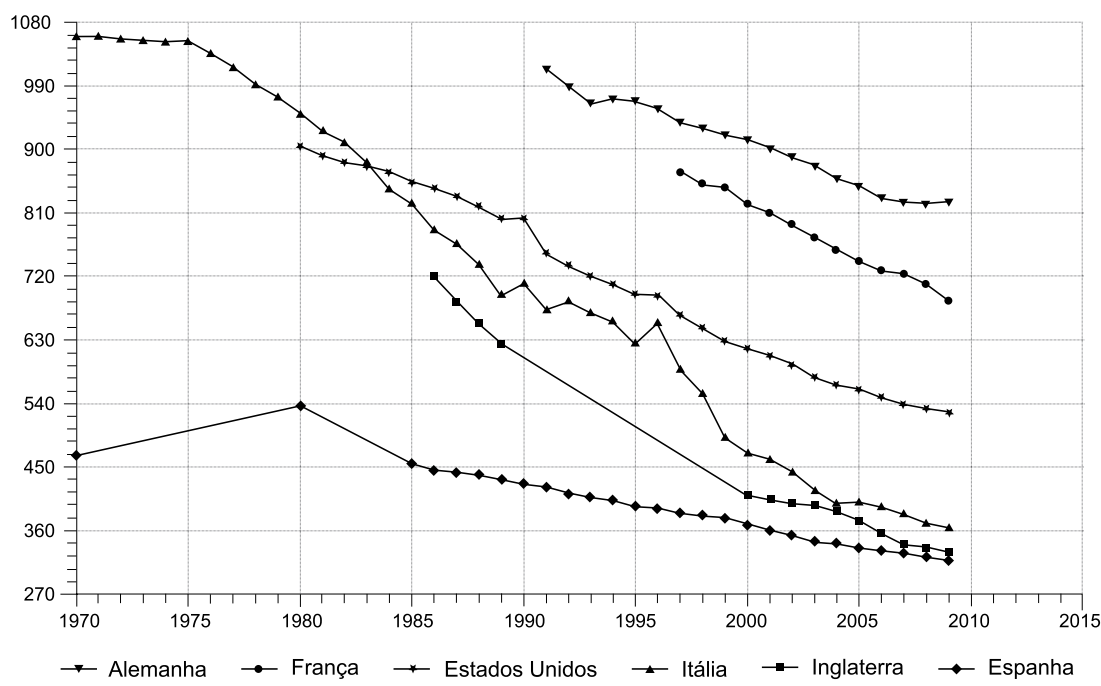

Fonte: WHO/Europe, European HFA Database, 2012a.

Gráfico 26 - Taxa de internação em países selecionados da Europa e no conjunto da União Europeia 1970-2006

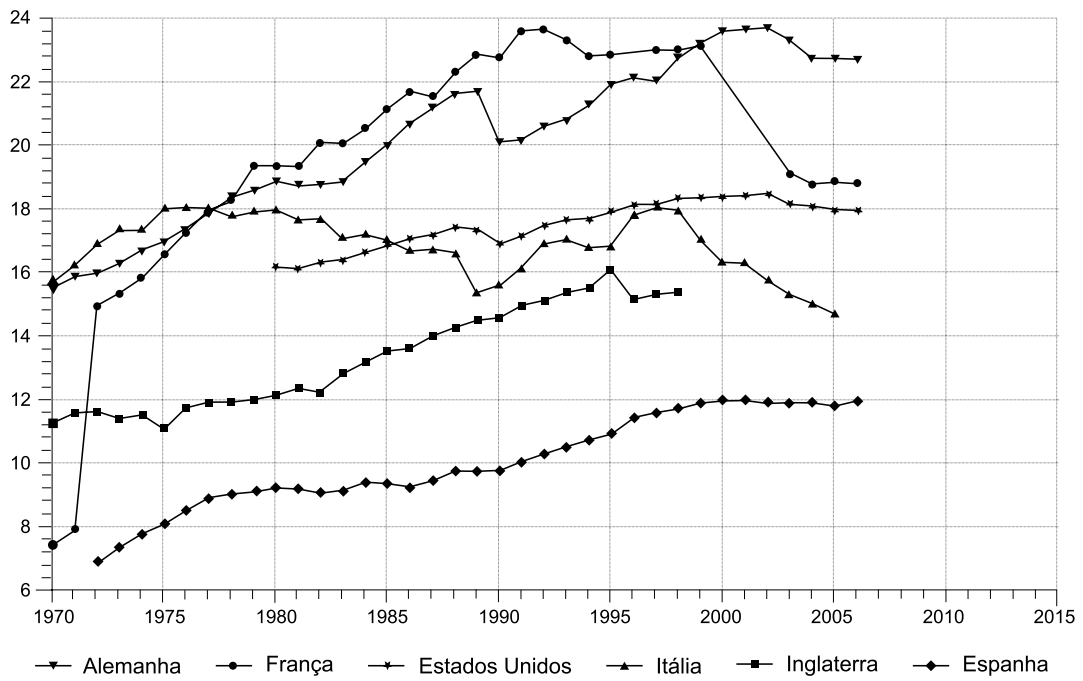

Fonte: WHO/Europe, European HFA Database, jan. 2009. 
Gráfico 27 - Tempo médio de permanência hospitalar (todos os hospitais) em países selecionados da Europa e no conjunto da União Europeia - 1970-2010

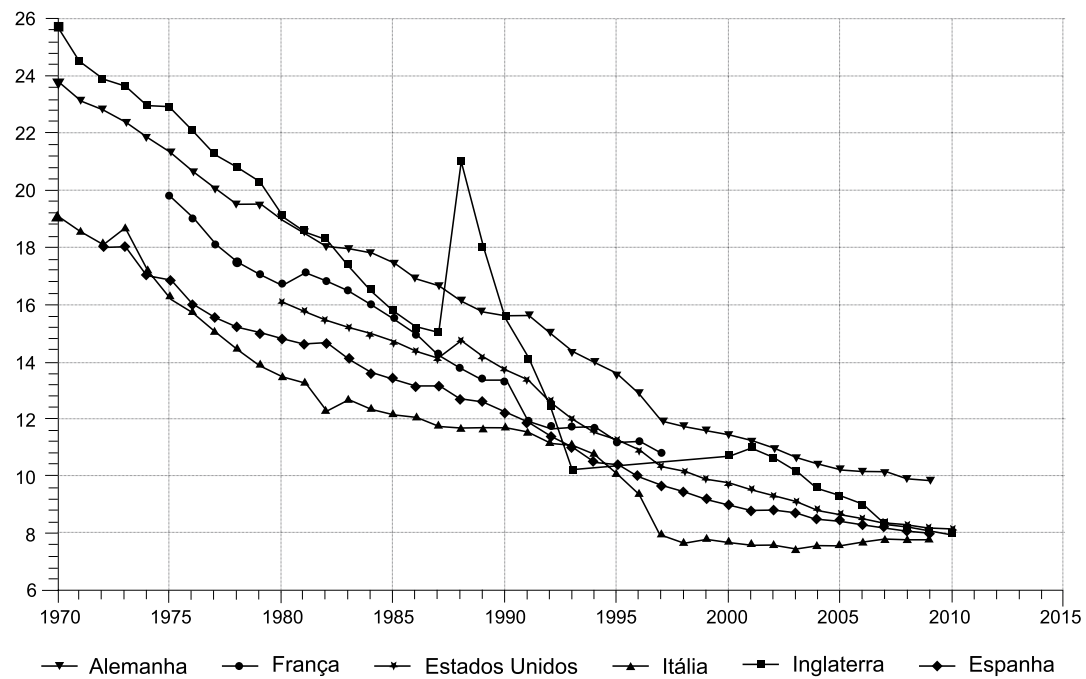

Fonte: WHO/Europe, European HFA Database, 2012a.

Gráfico 28 - Taxa de ocupação de leitos em hospitais para cuidados intensivos em países selecionados da Europa e no conjunto da União Europeia - 1970-2010

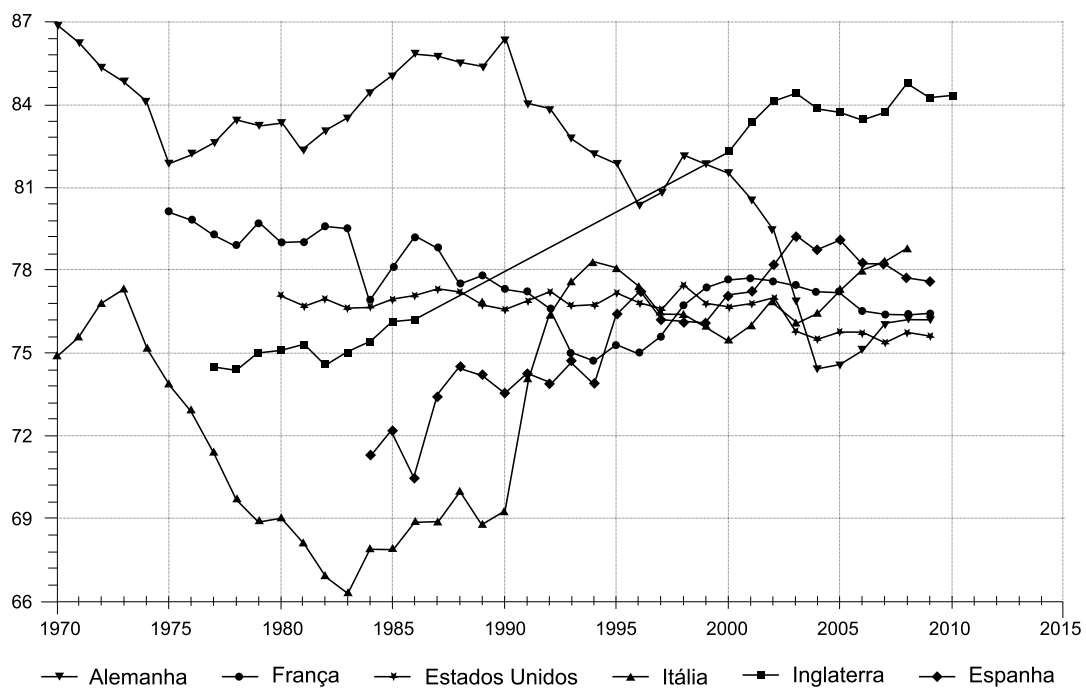

Fonte: WHO/Europe, European HFA Database, 2012a. 
Ou seja, o que está havendo é uma nítida alteração tecnológica no modelo assistencial no âmbito do sistema produtivo da saúde que altera o mix, de um lado, entre a utilização de serviços e bens industriais dos demais subsistemas (Produtos Químicos, Biotecnológicos, Equipamentos, Instrumentos e Materiais Médicos) e, de outro, entre as diversas modalidades assistenciais no interior do Subsistema de Serviços.

A complexidade do cuidado hospitalar, por sua vez, se intensifica e tem expressão singular nas despesas cada vez maiores com as internações (Gráfico 29). Configura-se um modelo ainda concentrado no hospital, mas que se transforma, voltando-se, cada vez mais, para casos agudos, com maior intensidade tecnológica e naturalmente com elevado peso nas despesas em saúde. Vale observar que a redução do número de hospitais e leitos (WHO, 2012a) não gera redução do peso das despesas hospitalares no conjunto dos gastos de saúde (Gráfico 30) em função da complexidade tecnológica crescente e dos custos que incorpora. Itália e Alemanha os mantêm estáveis em termos relativos, ao passo que França e Espanha diminuem seu peso no conjunto do sistema, esta última com queda mais significativa. Em todos os casos, dado o crescimento global das despesas em saúde, verifica-se importante crescimento das despesas não hospitalares, as quais são mais expressivas na Espanha (Gráfico 30).

Gráfico 29 - Gastos per capita com internações hospitalares em países selecionados da Europa e no conjunto da União Europeia - 1970-2009

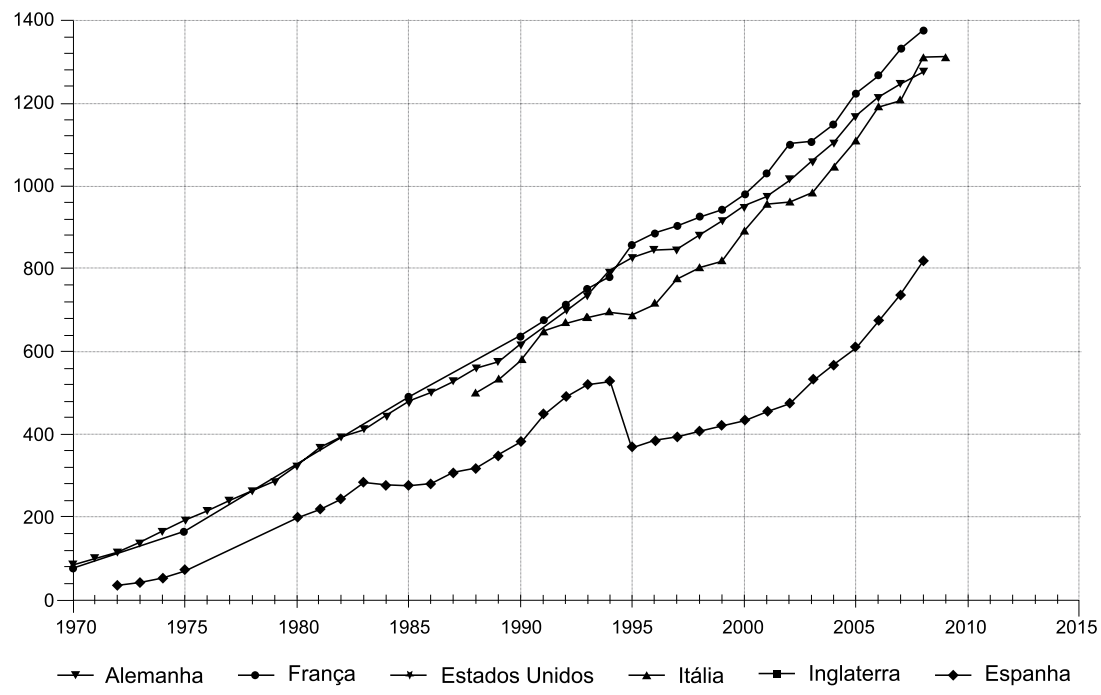

Fonte: WHO/Europe, European HFA Database, 2012a. 
Gráfico 30 - Gastos com internações hospitalares em relação aos gastos totais de saúde em países selecionados da Europa e no conjunto da União Europeia - 1970-2010

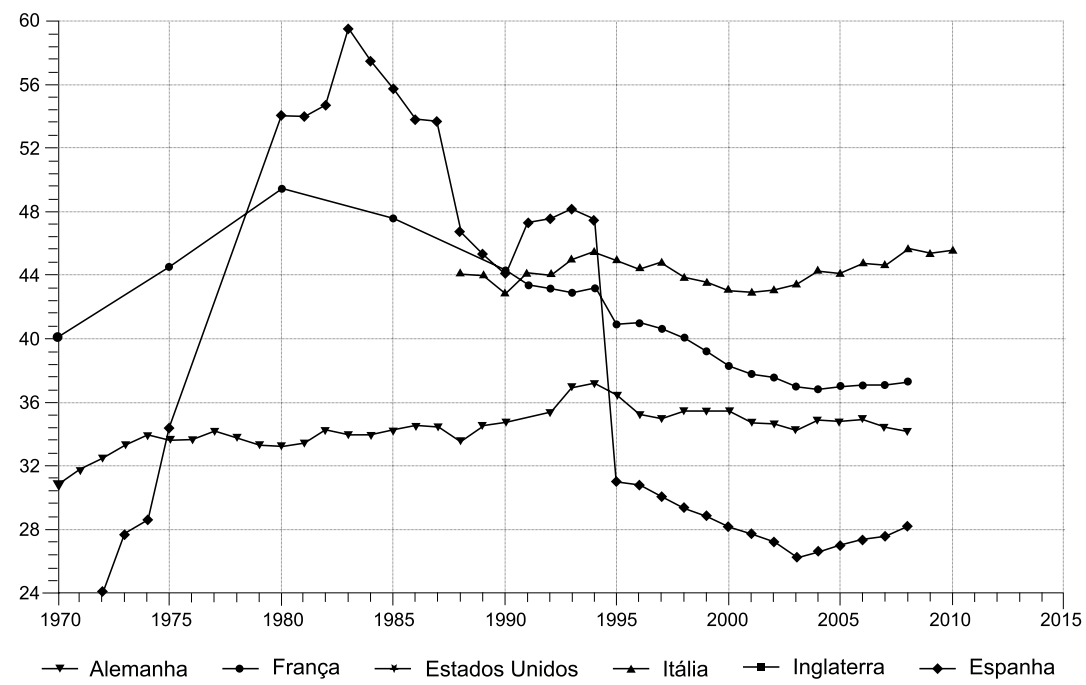

Fonte: WH0/Europe, European HFA Database, 2012a.

Todavia, na maioria dos países desenvolvidos os sistemas ainda são fortemente centrados no hospital e no médico, com limitação de serviços não hospitalares e não médicos, salvo aqueles destinados a idosos ou a cuidados de enfermagem e/ou voltados para situações crônicas de saúde, em que o cuidado não seja dependente do ato médico. Isso evidencia não uma ruptura com o paradigma assistencial dominante, mas sim um processo intenso de transformação das trajetórias tecnológicas e de alteração da direção e dos ritmos do progresso técnico. Esse processo de crescente intensificação tecnológica no paradigma dominante também pode ser atestado pela alta taxa de equipamentos médicos por habitante, muito embora isso se verifique em países com reconhecida regulação sobre incorporação de equipamentos, como França e Inglaterra (Tabela 30). ${ }^{27}$

Além da dinâmica intrínseca de evolução tecnológica, observa-se claramente que a realidade e as tendências interagem com os condicionamentos demográficos e epidemiológicos que modificam o perfil da demanda, com maior peso para os agravos crônicos e em populações mais idosas. São evidentes também suas dimensões financeiras, com a atenção das políticas públicas voltadas cada vez mais para o controle de gastos em saúde e para a busca de tecnologias assistenciais

${ }^{27}$ O Brasil se encontra a grande distância desses países em termos de disponibilidade de equipamentos, maior se considerados apenas os equipamentos disponíveis para o SUS, e ainda maior quando consideradas as regiões menos desenvolvidas do país (Brasil. Ministério da Saúde/Datasus, 2009). 
mais eficientes ou que apresentem uma relação custo-benefício socialmente mais adequada e sustentável.

Refletindo a alta participação dos gastos públicos em saúde e sua tendência de crescimento enfatizada anteriormente, o Gráfico 31 mostra o peso da participação do Estado nos gastos hospitalares. Sendo na média desses países o gasto público total em saúde próximo de $75 \%$, este patamar, quando especificados apenas os gastos públicos hospitalares, alcança média próxima de $90 \%$ de todos os gastos hospitalares. O que denota que a atenção hospitalar, em decorrência de seu elevado custo, é tomada como de maior responsabilidade pública em relação a outros serviços de saúde; também em termos internacionais, este é o segmento produtivo em que o gasto público é mais relevante, com desdobramentos para a importância do poder de compra público para todos os segmentos do CEIS.

Gráfico 31 - Gastos públicos com internações hospitalares em relação a gastos totais com internações em países selecionados da Europa e no conjunto da União Europeia - 1970-2010

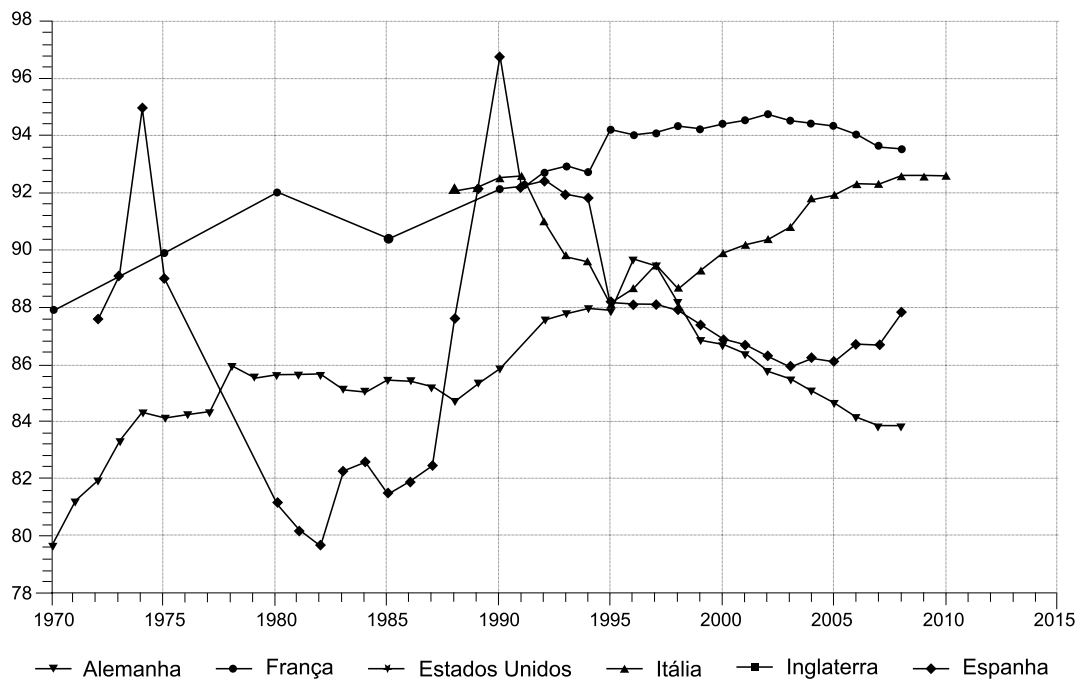

Fonte: WHO/Europe, European HFA Database, 2012a.

\section{TENDÊNCIAS DO INVESTIMENTO NO BRASIL}

Os Segmentos Público e Privado de Serviços de Saúde

No Brasil, como mencionado no capítulo 2, a realidade é peculiar, pois apesar de haver um sistema público, universal e integral, as limitações de financiamento público, que se situam significativamente abaixo da média dos países da Organização para a Cooperação e Desenvolvimento Econômico (OCDE), são expressivas. Uma visão geral do Subsistema de Serviços no Brasil - que, de certa forma, constitui a 
destinação final de todos os segmentos do CEIS - é mostrada no Tabela 31, envolvendo os gastos públicos por nível de governo e os desembolsos privados decorrentes das despesas com planos e seguros de saúde e aqueles realizados diretamente pelos indivíduos (do próprio bolso).

Tabela 31 - Gastos em serviços de saúde por segmento de mercado. Brasil - 2006

\begin{tabular}{l|c}
\hline SEGMENTOS DE MERCADO & VALOR (R\$ MILHÕES) \\
\hline Federal & 40.750 \\
\hline Estadual & 19.883 \\
\hline Municipal & 24.296 \\
\hline Total público & 84.929 \\
\hline Planos de saúde (ANS) & 41.858 \\
\hline Desembolso direto & 47.745 \\
\hline Total & 174.532 \\
\hline PIB Brasil & 2.332 .936 \\
\hline Despesa em saúde/PIB & $7,48 \%$ \\
\hline
\end{tabular}

ANS - Agência Nacional de Saúde

Fonte: dados apresentados pela Secretaria de Assistência à Saúde. Ministério da Saúde, 2008. (Títulos e formato alterados pelos autores).

Quanto aos gastos públicos relacionados com a operação do sistema universal, o Sistema Único de Saúde (SUS), observa-se a diminuição progressiva das despesas do governo federal, ao lado do aumento da participação relativa de estados e municípios no orçamento global da Saúde. Tal configuração reflete o formato descentralizado previsto tanto na Constituição de 1988 como na Lei Orgânica da Saúde (Lei 8.080 de 1990), com impacto expressivo na dinâmica do CEIS e nas formas de implementação das políticas de saúde em bases federativas. O Gráfico 32 apresenta a curva de gastos federais com importante queda relativa, ao lado dos expressivos aumentos de participação tanto de municípios quanto dos estados, havendo, no presente, participação relativa de um patamar de $50 \%$ do total de gastos no âmbito federal; os demais $50 \%$ estão distribuídos em cerca de $30 \%$ para os municípios e $20 \%$ para os estados.

Observe-se que, com toda restrição ao financiamento, o sistema público responde por $75 \%$ da atenção à população brasileira - não coberta pelo sistema privado -, sendo que cerca de $90 \%$ depende do SUS para os tratamentos de maior complexidade e, portanto, de maior intensidade tecnológica. Nesse contexto, os serviços públicos de saúde respondem anualmente por cerca de 3,2 bilhões de procedimentos ambulatoriais, mais de 450 milhões de consultas médicas e dois milhões de partos. Além disso, e evidenciando sua abrangência nas ações de maior complexidade, esses serviços 
realizam em torno de vinte mil transplantes, 280 mil cirurgias cardíacas, dez milhões de procedimentos de radio e quimioterapia e 11,4 milhões de internações. Ou seja, o SUS é, ao mesmo tempo, o principal mercado de serviços de saúde, de acesso da população e de incorporação tecnológica (Brasil. Ministério da Saúde, 2010).

Gráfico 32 - Tendências do investimento: percentuais dos gastos públicos (SUS) por fonte. Brasil $-2000-2009$

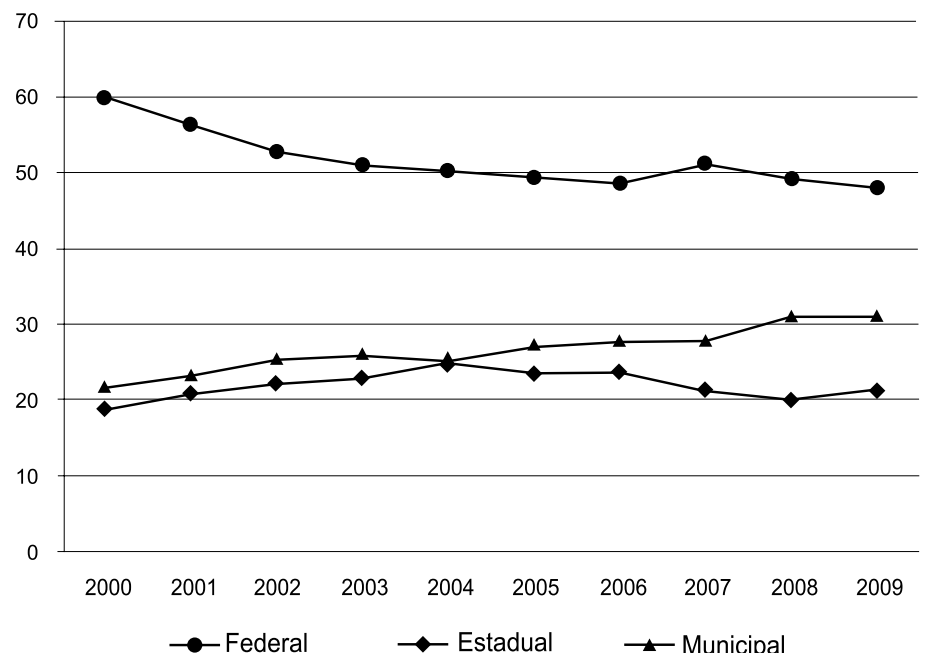

Fonte: elaborado por GIS/Ensp/Fiocruz, 2010. Para dados de 2000 a 2006, foram utilizados dados do Siops; SPO/SE; FNS/MS, 2008b; para dados de 2007 a 2009, dados do IBGE, 2012a.

Em paralelo, fruto em grande parte da insuficiência do financiamento público para viabilizar um sistema universal, observa-se importante crescimento do mercado privado de planos e seguros (Gráficos 33 e 34). Ainda que se considere o efeito estatístico da organização do sistema de informação do setor pela Agência Nacional de Saúde (ANS), é reconhecido que esse mercado continua se expandindo, alcançando valores de faturamento superiores ao investimento público federal no SUS, para um conjunto de beneficiários estimado em cerca de $32 \%$ da população brasileira e com tendência a crescimento, apesar do provável arrefecimento decorrente da crise atual. A concentração deste segmento em planos coletivos, em sua maior parte financiados por empresas, está associada ao recente dinamismo econômico e social do país. Certamente, os limites de acesso e qualidade do sistema público condicionam tal desempenho, combinado com limitações nos investimentos públicos em saúde.

Como decorrência do papel regulador da ANS e ainda como tendência identificada também no mercado internacional, o setor de planos e seguros apresenta clara tendência à diminuição de operadoras (Gráfico 35). Tem expressado sinais de busca de escala, envolvendo um crescente número de beneficiários por operadora para a diluição dos 
riscos associados aos requerimentos de equilíbrio econômico-financeiro e às despesas com diferentes grupos de consumidores, praticando taxas de sinistralidade diferenciadas (jovens e idosos, populações mais ou menos suscetíveis a determinadas doenças etc.). A dinâmica de mercado opera, assim, com uma tendência à concentração, o que denota um processo de fechamento de pequenas operadoras e de fusões e/ou incorporação de empresas. O Gráfico 36 mostra que, apesar de o mercado contar com mais de 1.600 operadoras, 185 são responsáveis por mais de $80 \%$ dos beneficiários de planos; tal concentração se mostra ainda mais relevante quando se leva em conta que a competição neste segmento se expressa em termos regionais e locais, âmbitos em que invariavelmente se verificam, sobretudo no interior, situações de monopólio ou duopólio.

Gráfico 33 - Tendências do investimento: receitas das operadoras de planos de saúde. Brasil - 20032010 (em R\$ bilhões)

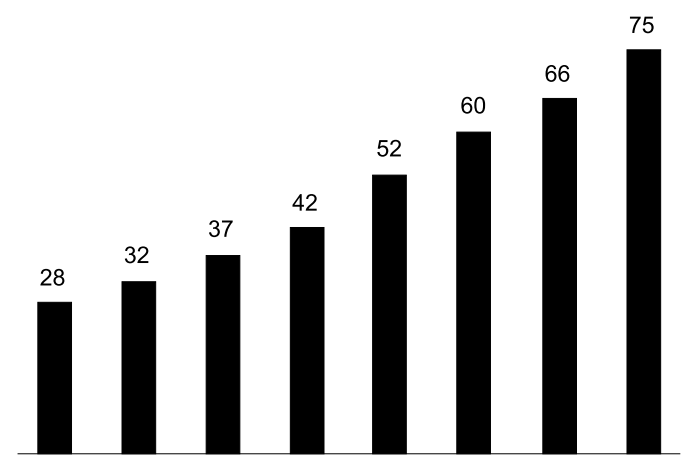

dez/03 dez/04 dez/05 dez/06 dez/07 dez/08 dez/09 dez/10

0 crescimento das receitas é também fruto da melhoria na captação de informações pela ANS, expressando apenas parcialmente 0 crescimento real.

Fonte: elaborado por GIS/Ensp/Fiocruz com base em dados da ANS, 2011.

Gráfico 34 - Beneficiários de plano de saúde por cobertura assistencial do plano. Brasil - 2000-2010

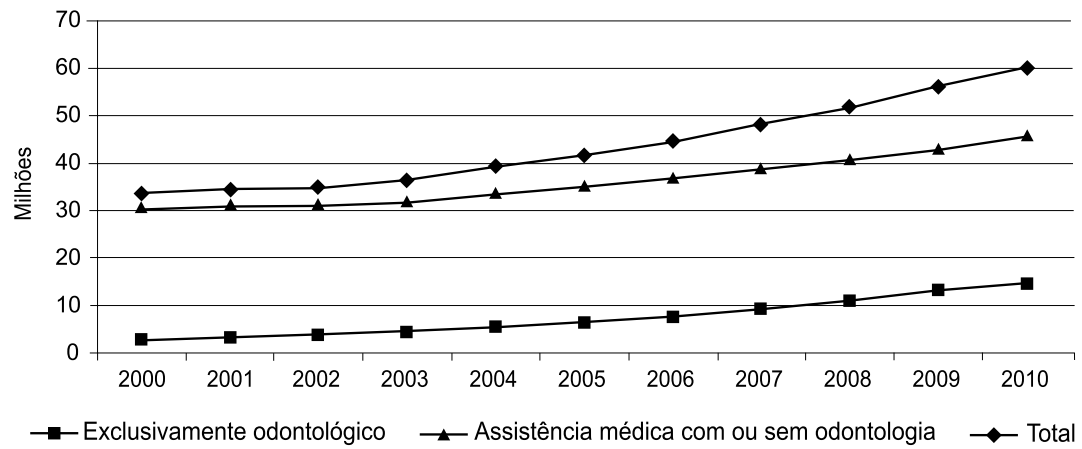

0 termo ‘beneficiário’ refere-se a vínculos com planos de saúde, podendo incluir mais de um vínculo para o mesmo indivíduo. Fonte: elaborado por GIS/Ensp/Fiocruz, a partir de dados da SIB/ANS/MS (ANS, 2011). 
Gráfico 35 - Serviços de saúde: dados da saúde suplementar. Número de operadoras. Brasil 2000-2010

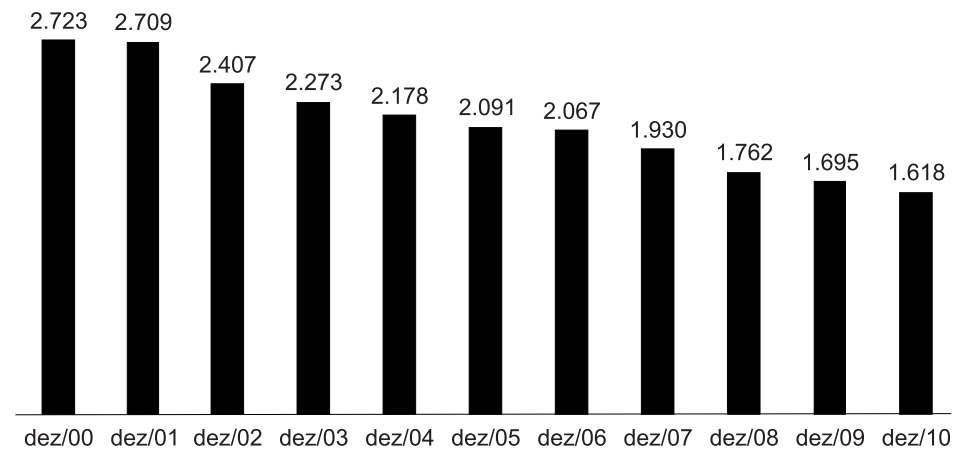

Fonte: elaborado por GIS/Ensp/Fiocruz, a partir de dados da ANS, 2011.

Gráfico 36 - Distribuição de beneficiários de planos de saúde de assistência médica por operadoras. Brasil - 2011

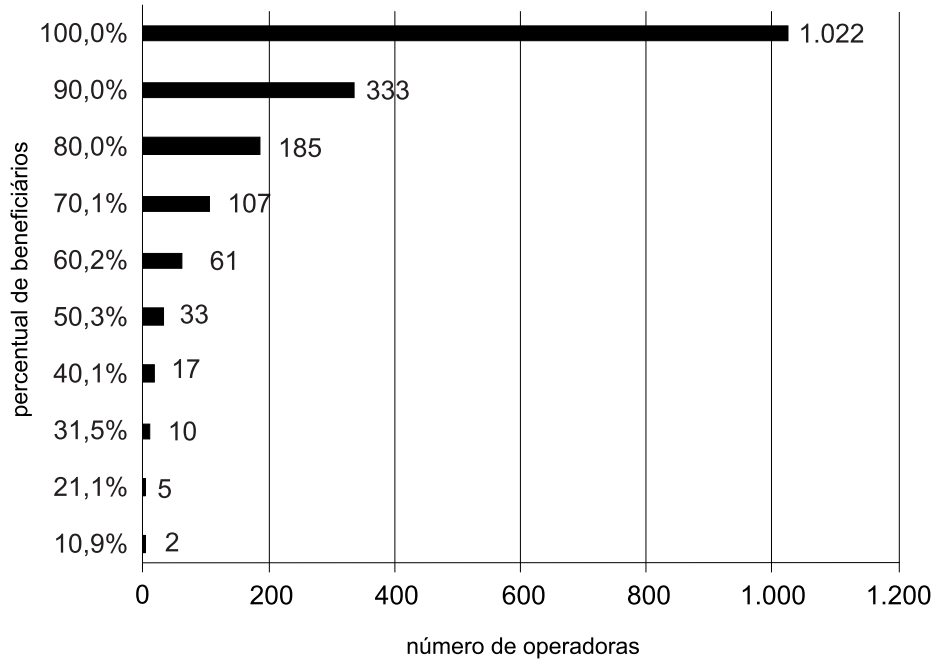

Fonte: elaborado com base nos dados da ANS, 2011.

Tendências nos Sistemas Nacionais de Saúde e Estrutura de Serviços de Saúde com Foco no Segmento Hospitalar

Será apresentada aqui uma descrição do panorama atual e das tendências para o desenvolvimento do Subsistema de Serviços no Brasil, com ênfase no setor hospitalar e nos serviços de diagnóstico e terapia. Serão identificados os principais desafios e gargalos de desenvolvimento, os principais agentes e seus papéis. 
A análise do panorama atual dos serviços hospitalares no país toma como base a pesquisa sobre a Assistência Médico-Sanitária, AMS (IBGE, 2010c), apresentando a rede hospitalar brasileira em três grandes conjuntos de hospitais: os privados lucrativos, os privados não lucrativos e os públicos. A participação dos três segmentos no que se refere ao número de leitos é bastante similar, todos próximos de $30 \%$ do total.

Em relação a essa distribuição de hospitais, o Brasil, por sua natureza, de forma distinta de outros países, tem no segmento lucrativo uma expressão quantitativa importante, chegando a alcançar 40\% dos leitos (IBGE, 2010c). Sloan (2000), em artigo sobre hospitais não lucrativos em vários países do mundo, relata existência minoritária de hospitais lucrativos em tais países. Destaca, inclusive, o fato de ser mesmo proibida, na Holanda, a existência de hospitais lucrativos. Marinho (2004) registra que o Brasil, quanto à presença de hospitais lucrativos, encontra-se no patamar superior em comparação a outros países; e que nos países menos desenvolvidos essa participação seria maior que naqueles em estágio de desenvolvimento mais avançado.

De todo modo, registra-se no Brasil uma tendência, que se acentua nas últimas décadas, ao equilíbrio no número de leitos públicos quando comparado ao número de leitos privados, lucrativos e não lucrativos. Esse fenômeno está associado tanto à diminuição do setor privado - lucrativo e não lucrativo - quanto à expansão do setor público, conforme o Gráfico 37.

Quando observado em separado, o número de hospitais do país, no mesmo período, registra um crescimento expressivo, elevando-se no período de 1976 a 2005 em 29,4\%, com um salto de 5.311 para 6.875 estabelecimentos (IBGE, 2010c). Natural que esse processo - diminuição do número de leitos com crescimento do número de hospitais - tenha decorrido da abertura de hospitais com menor número de leitos, muito certamente associada ao fechamento de hospitais com números superiores de leitos.

o Gráfico 38 registra a queda histórica do número médio de leitos no parque hospitalar público: em trinta anos, houve a redução para quase um terço da média registrada em 1976 - de 124 para 54 leitos por hospital em 2005. De 2005 para 2009, houve diminuição da taxa de leitos, que caiu de 2,4 para 2,3 leitos por mil habitantes (IBGE, 2010C).

O segmento privado também apresenta redução no número médio de leitos, embora menos expressiva. Essa tendência à diminuição da média de leitos por estabelecimento foi permanente nos últimos trinta anos, quando o parque de estabelecimentos públicos com internação no país triplicou. Considerando em particular o período a partir da implantação do SUS, em 1990, foram abertos no país 693 hospitais públicos, com média de 34,8 leitos por unidade (AMS/IBGE, 2006). Uma explicação a ser considerada 
é a base municipalista do sistema, que fomenta hospitais locais de pequeno porte e limitada densidade tecnológica.

Os dados registram que a dinâmica dos hospitais e do número de leitos no país expressa um aparente paradoxo e muito certamente um grande desafio para o futuro da atenção hospitalar no país. Seria esperada, como ocorre em outros países, a diminuição na relação leitos por habitantes, notória no Brasil, mas acompanhada do incremento tecnológico dos hospitais, o que impõe a existência de hospitais de porte médio, dadas as duas condições básicas e interdependentes. A primeira é a incorporação de tecnologias ao ambiente hospitalar, que permite tanto a realização de procedimentos em menores tempos de internação quanto a ambulatorização de procedimentos antes exclusivamente hospitalares. A outra condição é a enorme expansão de cobertura e também a incorporação tecnológica dos serviços extrahospitalares, que gera importante alteração na demanda por hospitalizações. Quando gerada pós-atenção inicial fora do hospital, a demanda hospitalar tende a exigir maior complexidade assistencial. A essas duas condições básicas somamse o próprio perfil epidemiológico, alterado por condições demográficas novas, e a emergência de novos fatores de risco a impactar o processo saúde-doença. Há, em síntese, forte tendência à redução da necessidade de leitos hospitalares, no entanto, obrigatoriamente com maior densidade tecnológica agregada.

Gráfico 37 - Número de leitos em estabelecimentos públicos e privados (lucrativos e não lucrativos) com internação no período. Brasil - 1976-2009

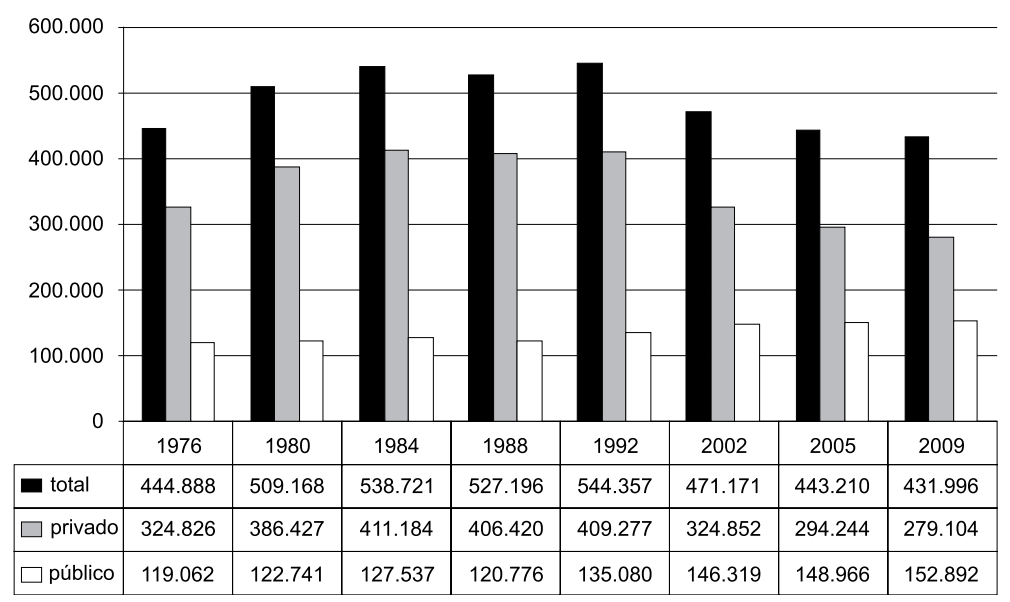

Fonte: elaborado pelo GIS/Ensp/Fiocruz, a partir de dados da AMS/BGE, 2010c. 
Gráfico 38 - Número médio de leitos em estabelecimentos públicos e privados (lucrativos e não lucrativos) com internação no período. Brasil - 1976-2009

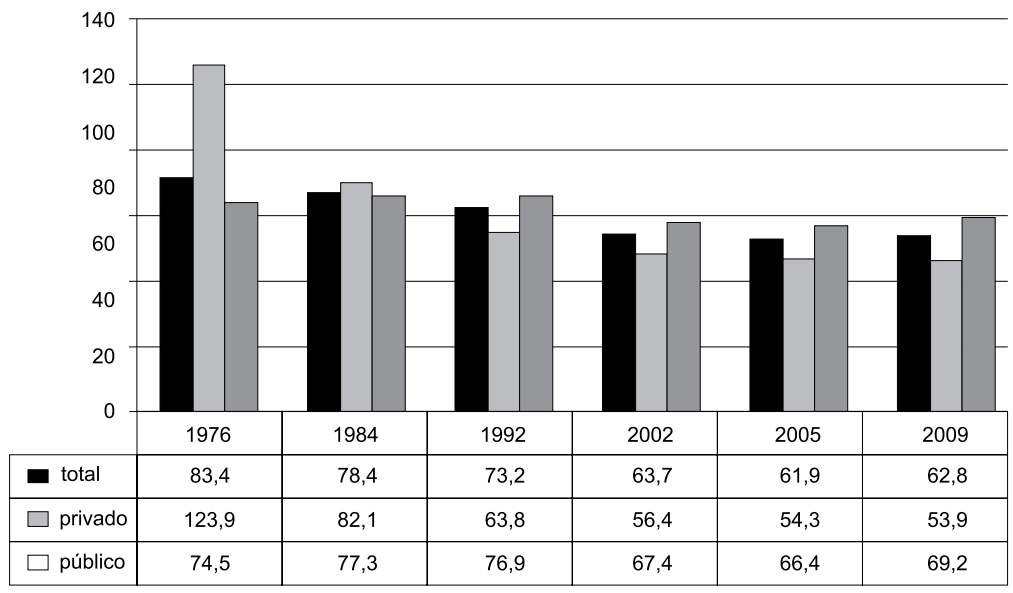

Fonte: elaborado pelo GIS/Ensp/Fiocruz, a partir de dados da AMS/IBGE, 2010c.

A maior densidade ou complexidade tecnológica no ambiente hospitalar, em função da incorporação tanto de equipamentos e insumos quanto de profissionais mais diferenciados, exige, por sua vez, escalas economicamente sustentáveis. Ao contrário do observado no Brasil, a escala média de leitos dos hospitais brasileiros, combinada com a diminuição de leitos no total, deveria crescer, e não diminuir. Aqui reside o paradoxo e certamente o grande desafio para o futuro imediato da atenção e gestão hospitalar brasileira. O país não estaria, no seu parque hospitalar, acompanhando tanto as tendências internacionais no campo da atenção e gestão hospitalar quanto as suas próprias necessidades epidemiológicas. O ajuste observado, com diminuição do número total de leitos, acompanhado de diminuição do número médio de leitos por hospital, não corresponderia ao esperado ajuste na oferta de serviços hospitalares, especialmente quanto às novas exigências tecnológicas e econômicas na atenção e gestão hospitalar.

Concomitantemente à dinâmica dos hospitais, o país operou um processo inigualável de expansão de cobertura da atenção básica não hospitalar nas três últimas décadas, quando viu o número de estabelecimentos sem oferta de internação saltar de 7.822, em 1976, para 67.901, em 2009. Esse crescimento foi maior no setor público, basicamente em decorrência das políticas públicas, e em particular do SUS, após os anos 1990 (IBGE, 2006). Dados de 2010 (IBGE, 2010c) registram expressivo parque de serviços, considerando tanto hospitalares (serviços com internação) quanto não hospitalares e os serviços de diagnose (Tabela 32). 
Tabela 32 - Número de estabelecimentos de serviços de saúde por esfera administrativa. Brasil - 2009

\begin{tabular}{l|c|c|c|c}
\hline ESEERA ADMINISTRATIVA & COM INTERNAÇÃO & SEM INTERNAÇ̃̃o & DIAGNOSE & TOTAL \\
\hline Públicos & 2.839 & 47.414 & 1.768 & 52.021 \\
\hline Privados & 4.036 & 20.487 & 17.526 & 42.049 \\
\hline Total & 6.875 & 67.901 & 19.294 & 94.070 \\
\hline
\end{tabular}

Fonte: AMS/IBGE, 2010c.

$\mathrm{Na}$ área hospitalar houve, no mesmo período, importante consequência na dinâmica das internações. Em 1995, tomando-se por referência apenas o SUS, foram realizadas 13,28 milhões de internações. Esse número decresceu sucessivamente até alcançar 11,29 milhões em 2006. Em 1995, registravam-se 85 Autorizações de Internação Hospitalar (AIHs) para cada mil habitantes, enquanto em 2006 esse número caiu para 61. Essas mudanças decorreram da definição de novos parâmetros de distribuição de AIHs e de tetos financeiros para gastos hospitalares por estado. Acompanhando as tendências, tanto de oferta quanto de demanda, e as estratégias dos prestadores de serviços de saúde, as AlHs emitidas registram um importante crescimento na complexidade da atenção prestada. Só entre os anos de 1995 e 1999, as AIHs que correspondem a internações de alta complexidade cresceram 104\% (Spigolon, 2002).

No caso das políticas ditas implícitas, destaca-se o controle do número de internações, combinado com relativo incentivo a internações de maior complexidade e a demandar tecnologias diferenciadas agregadas ao leito. Esse processo contribui para segmentar o parque hospitalar a serviço do SUS, muito provavelmente gerando um conjunto mais dinâmico de hospitais, que incorporam tecnologias, alcançam outras mais novas ou estabilizam escalas de produção economicamente mais sustentáveis (tomando-se por base o número de leitos).

Dados do Cadastro Nacional de Estabelecimentos de Saúde (CNES) registravam, em 2006, apenas 293 hospitais no país com 201 leitos ou mais, representando apenas $4 \%$ dos hospitais integrantes do SUS - públicos e privados; no outro extremo, 39\%, ou 2.659, dos hospitais do SUS possuíam até trinta leitos, com menor dinamismo e limitada incorporação tecnológica.

Consagram-se pelo menos duas tendências. No segmento dito superior, o polo dinâmico, mais próximo das características registradas internacionalmente, com hospitais de médio e grande portes, com maior densidade tecnológica, potencialmente mais sustentáveis em termos econômicos e respondendo por demandas crescentes ajustadas epidemiologicamente. $\mathrm{Na}$ base, os pequenos hospitais, tendendo a ter sua função assistencial substituída, ao menos em parte, por serviços extra-hospitalares mais eficientes e eficazes. 
Os dados sobre porte dos hospitais acabam por determinar importante desafio e gargalo na dinâmica econômica do subsegmento. Estudos recentes (La Forgia \& Couttolenc, 2008) apresentam importante limitação no desempenho de hospitais com pequenas escalas de leitos, conforme Gráfico 39.

Gráfico 39 - Desempenho e escala de hospitais brasileiros (Padrão DEA)

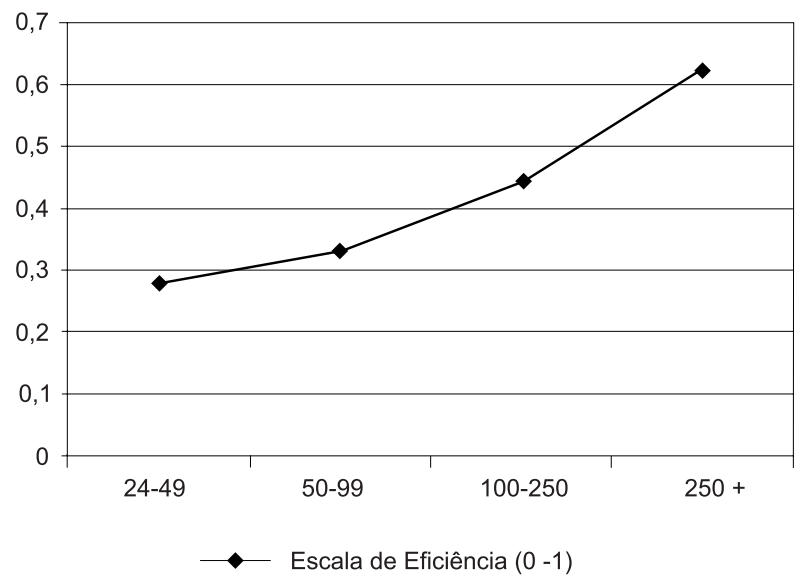

DEA - Data Envelopment Analysis

Fonte: World Bank, 2008.

\section{PERSPECTIVAS A MÉDIO E LONGO PRAZOS PARA OS INVESTIMENTOS}

Perspectivas a Médio Prazo: cenário possível

Conforme a metodologia geral deste estudo, o cenário possível é construído com base no contexto das políticas vigentes, sendo, para o Subsistema de Serviços, referência básica o Programa Mais Saúde do governo federal, em vigor desde 2008 e com objetivos, metas e despesas previstos até 2011.

Nesse contexto, observam-se tendências a que o aumento dos gastos em saúde supere o crescimento do PIB, mantido em especial o crescimento dos gastos municipais e estaduais, e a que sejam propostas fontes de financiamento alternativas e complementares àquelas decorrentes da efetiva regulamentação da Emenda Constitucional 29, de modo a também elevar de forma mais significativa os gastos federais. A tendência recente, portanto, é que se estabeleça uma relação entre os gastos em saúde e o crescimento do PIB, tanto no setor público quanto no privado. No entanto, alternativas concretas para o incremento de gastos federais a médio prazo estão associadas à regulamentação de emenda constitucional que possibilitaria compromissos com gastos federais associados à arrecadação e nítido incremento de receitas no setor. No setor privado, por sua vez, o crescimento dos últimos anos, 
superior ao do setor público, pode arrefecer, acompanhando a própria tendência de desaceleração da economia, dada a estreita relação deste subsegmento com o crescimento geral da economia. Assim, nesse prazo médio, haveria alterações nos macroindicadores de financiamento e gastos no segmento de serviços de saúde. No período, os gastos públicos podem se elevar a $5 \%$ do PIB, com o total dos gastos em saúde mantidos em patamares entre $8 \%$ e 9\% deste indicador. Nesse cenário, haveria inversão entre gastos públicos e privados em saúde, com os primeiros alcançando patamares superiores a $50 \%$ do total de gastos. ${ }^{28}$

A Tabela 33 sintetiza as principais ações nas diversas dimensões do Mais Saúde, destacando os investimentos previstos para o período, tanto nas dimensões desenvolvimento tecnológico quanto na expansão da base produtiva.

Tabela 33 - Investimentos previstos e nichos tecnológicos e de mercado. Programa Mais Saúde com impacto nos serviços - 2008-2011

\begin{tabular}{|c|c|c|c|}
\hline NICHOS TECNOLÓGICOS E DE MERCADO & $\begin{array}{l}\text { DENSIDADE } \\
\text { TECNOLÓGICA }\end{array}$ & $\begin{array}{l}\text { INVESTIMENTOS } \\
\text { PREVISTOS } \\
\text { (R\$ MIL) }\end{array}$ & INSTITUIÇÕES AGENTES \\
\hline \multicolumn{4}{|l|}{ DESENVOLVIMENTO TECNOLÓGICO (DT) } \\
\hline Implantar duas redes para suporte à incorporação tecnológica & Média & 24.000 & Ministério da Saúde \\
\hline $\begin{array}{l}\text { Fortalecer centros de pesquisa e desenvolvimento para apoio } \\
\text { à indústria e aos serviços }\end{array}$ & Média/Alta & 149.868 & $\begin{array}{l}\text { Ministério da Saúde, } \\
\text { Fiocruz }\end{array}$ \\
\hline Implantar duas redes de pesquisas clínicas & Média & 11.666 & $\begin{array}{l}\text { Ministério da Saúde, } \\
\text { Fiocruz, universidades }\end{array}$ \\
\hline SUBTOTAL DT & & 185.534 & \\
\hline
\end{tabular}

EXPANSÃO E TRANSFORMAÇÃO DA BASE PRODUTIVA

\begin{tabular}{l|c|c}
\hline Ações diversas de promoção da saúde & 125.803 & SUS \\
\hline $\begin{array}{l}\text { Ampliar e qualificar rede de atenção básica, com ênfase no } \\
\text { Programa Saúde da Família (PSF) }\end{array}$ & 1.531 .101 & SUS \\
\hline Expandir o Serviço Móvel de Atendimento de Urgência (Samu) & 533.802 & SUS \\
\hline Ampliar rede própria de farmácias populares & 39.128 & SUS \\
\hline $\begin{array}{l}\text { Expandir rede de farmácias populares de mercado e ampliar } \\
\text { número de medicamentos }\end{array}$ & 1.222 .657 & SUS \\
\hline Expandir internações domiciliares & 252.148 & SUS
\end{tabular}

${ }^{28}$ Note-se que não houve a inversão entre os gastos públicos e privados no período, mas sim expansão proporcional dos gastos públicos em relação ao privado; atualmente aqueles respondem por $44 \%$ do gasto total em saúde no Brasil (IBGE, 2012a). 
Tabela 33 - Investimentos previstos e nichos tecnológicos e de mercado. Programa Mais Saúde com impacto nos serviços - 2008-2011 (continuação)

\begin{tabular}{|c|c|c|c|}
\hline NICHOS TECNOLÓGICOS E DE MERCADO & $\begin{array}{l}\text { DENSIDADE } \\
\text { TECNOLÓGICA }\end{array}$ & $\begin{array}{l}\text { INVESTIMENTOS } \\
\text { PREVISTOS } \\
(\mathrm{R} \$ \text { MIL) }\end{array}$ & $\begin{array}{l}\text { INSTITUICCÕES } \\
\text { AGENTES }\end{array}$ \\
\hline \multicolumn{4}{|l|}{ EXPANSÃO E TRANSFORMAÇÃO DA BASE PRODUTIVA } \\
\hline Ações diversas de promoção da saúde & & 125.803 & SUS \\
\hline $\begin{array}{l}\text { Ampliar e qualificar rede de atenção básica, com ênfase no Programa } \\
\text { Saúde da Família (PSF) }\end{array}$ & & 1.531 .101 & SUS \\
\hline Expandir o Serviço Móvel de Atendimento de Urgência (Samu) & & 533.802 & SUS \\
\hline Ampliar rede própria de farmácias populares & & 39.128 & SUS \\
\hline $\begin{array}{l}\text { Expandir rede de farmácias populares de mercado e ampliar número } \\
\text { de medicamentos }\end{array}$ & & 1.222 .657 & SUS \\
\hline Expandir internações domiciliares & & 252.148 & SUS \\
\hline Expandir consultas e exames especializados - saúde do homem & & 20.249 & SUS \\
\hline Ampliar acesso a controle de diabetes e hipertensão & & 764.405 & SUS \\
\hline Oferta de novas vacinas & & 389.943 & SUS \\
\hline Implantar unidades de respostas rápidas a emergências & & 15.482 & \\
\hline Expandir serviços médicos e odontológicos de média complexidade & & 440.829 & SUS \\
\hline Expandir rede de atenção ao câncer & & 1.122 .472 & SUS \\
\hline Ampliar acesso a diversos procedimentos diagnósticos e terapêuticos & & 6.965 .583 & SUS \\
\hline Expandir e modernizar hospitais & & 2.999 .391 & SUS \\
\hline Ampliar leitos de UTI e semi-intensivos & & 1.262 .901 & SUS \\
\hline Ampliar transplantes & & 1.174 .948 & SUS \\
\hline Expandir laboratórios de saúde pública & & 40.613 & SUS \\
\hline Expandir serviços de armazenamento & & 63.360 & SUS \\
\hline Criar centros de emergências obstétricas e neonatais & & 4.000 & SUS \\
\hline Instalar nova escola de saúde pública & & 20.500 & Fiocruz \\
\hline SUBTOTAL EXPANSÃO & & 18.989 .315 & \\
\hline TOTAL & & 19.174.849 & \\
\hline
\end{tabular}

(1) Os nichos na dimensão DT foram identificados exclusivamente a partir do eixo Complexo Industrial da Saúde (Mais Saúde); (2) Os nichos relacionados com a expansão e transformação da base produtiva foram identificados a partir dos eixos Promoção da Saúde e Atenção à Saúde; (3) Apenas um nicho na dimensão Expansão e Transformação da Base Produtiva foi identificado no eixo Força de Trabalho em Saúde (instalar escola de saúde pública); (4) Não foram identificados nichos de DT ou Expansão da Base Produtiva nos eixos Cooperação Internacional, Participação e Controle Social e Qualificação da Gestão; (5) Os valores são estimados, pois 0 programa não discrimina, na maioria das ações, a manutenção de atividades que implicam crescentes gastos de capital e custeio.

Fonte: Programa Mais Saúde (PAC da Saúde) - Brasil. Ministério da Saúde, 2007. 
Quanto ao processo de estruturação do mercado, este deve seguir com o enxugamento do número de operadoras, projetando-se uma redução para um número inferior a mil ao fim do período, com fechamento ou incorporações superiores a $10 \%$ ao ano. Segue o fechamento de hospitais e leitos, quase que exclusivamente privados e sobretudo no âmbito dos serviços de diagnose, uma nítida e relativamente acelerada concentração (quando comparada com os subsegmentos de hospitais e operadoras de planos e seguros), com movimentos de aquisições e incorporações bastante disseminadas. Há tendência clara à oligopolização deste mercado. É parte ainda da estratégia dos maiores grupos a prestação de serviços intra-hospitalares, por meio de associações ou terceirizações. Neste subsegmento, até setembro de 2011 cerca de $3 \%$ das operadoras do país concentravam mais de $50 \%$ do número de beneficiários do mercado privado (ANS, 2011). Há ainda sinais a serem explorados quanto a associações deste subsegmento com a indústria de equipamentos e reagentes para diagnóstico, de forma a evidenciar a interdependência sistêmica.

Ainda no setor privado, a perspectiva de racionalização dos custos tem gerado processos nítidos de verticalização, envolvendo operadoras de planos, hospitais e serviços de diagnose. Esse movimento é percebido com nitidez especialmente entre operadoras, que incorporam ou constroem hospitais e investem, ainda que em menor escala, em serviços de diagnóstico. Igualmente operam processos de diversificação para serviços pré e pós-hospitalares, tais como atenção e internações domiciliares e implantação de hospitais-dia.

No âmbito do setor público, com importantes limites para investimentos de maior monta, há opções por investimentos focalizados, concentrados, entre outros, na expansão de serviços pré-hospitalares, como o Serviço Médico de Urgência (Samu), e na implantação de leitos de maior complexidade, como de terapia intensiva; e ainda por movimentos de natureza incremental em aspectos organizativos do sistema, como a implantação e disseminação de centrais de regulação de acesso e utilização da rede de serviços. As principais ações, bem como os recursos mais significativos, encontravam-se previstos no Programa Mais Saúde.

No cenário de médio prazo, salvo alterações de alguma monta no subsegmento privado, não são identificados movimentos mais significativos na tendência dos investimentos públicos. Ainda no setor privado, tanto de operadoras de planos de saúde quanto de hospitais e serviços de diagnose, o que se observa é a busca de economias de escala, a partir de processos de incorporações, fusões, combinados ou não com verticalizações. Alterações de escopo são também visíveis, com alguma diversificação da oferta neste subsegmento de serviços de saúde, quase sempre em direção à desospitalização. Em entrevistas, dirigentes do setor hospitalar privado informam sobre algumas associações de grupos hospitalares privados nacionais com hospitais de outros países, visando à atratividade para mercados internacionais (sobretudo latinoamericanos), agregando valor tanto na dimensão da gestão quanto na atenção.

Há ainda associações já firmadas com grupos de investidores internacionais, prestadores de serviços hospitalares internacionais e nacionais, para disputa de 
editais públicos de Parcerias Público-Privadas (PPPs) em hospitais. Essa modalidade de investimento na área de saúde deverá se expandir nos próximos anos.

O Quadro 12 sintetiza o cenário a médio prazo, cuja formulação seguiu a orientação estratégica definida na época do Mais Saúde como referência.

\section{Quadro 12 - Perspectivas a médio prazo. Cenário possível - 2012}

\begin{tabular}{|c|c|c|c|}
\hline $\begin{array}{l}\text { DETERMINANTES DA DINÂMICA } \\
\text { DO INVESTIMENTO ESPERADO }\end{array}$ & METAS PARA 2012 & $\begin{array}{l}\text { IMPACTOS NO SUBSISTEMA DE } \\
\text { SERVIÇOS }\end{array}$ & $\begin{array}{l}\text { EFEITOS ESPERADOS NO } \\
\text { CONJUNTO DA ECONOMIA }\end{array}$ \\
\hline $\begin{array}{l}\text { Implementação do Programa } \\
\text { Mais Saúde (PAC da Saúde). } \\
\text { Expansão da participação } \\
\text { pública nos gastos saúde. } \\
\text { Novos mecanismos de } \\
\text { contratação de serviços } \\
\text { públicos e privados no } \\
\text { âmbito do SUS. } \\
\text { Aumento do número de } \\
\text { hospitais públicos e privados } \\
\text { com adequada incorporação } \\
\text { tecnológica e escala de } \\
\text { produção eficiente. } \\
\text { Atratividade da área de } \\
\text { serviços para investimentos } \\
\text { externos - incremento } \\
\text { da ameaça competitiva } \\
\text { - pressão por escala, } \\
\text { eficiência, entre outros. } \\
\text { Ampliação do uso de } \\
\text { tecnologias mais intensivas } \\
\text { no âmbito dos serviços } \\
\text { - equipamentos e novas } \\
\text { tecnologias de informação e } \\
\text { comunicação. } \\
\text { Aumento da participação de } \\
\text { leitos de tecnologia intensiva } \\
\text { no total de leitos hospitalares. } \\
\text { Adequaçãa do arcabouço de } \\
\text { gestão pública gerando mais } \\
\text { eficiência no gasto e relações } \\
\text { mais dinâmicas envolvendo } \\
\text { o setor privado prestador de } \\
\text { serviços de saúde. }\end{array}$ & $\begin{array}{l}\text { Aumento nos gastos públicos } \\
\text { em saúde para } 5 \% \text { do PIB. } \\
\text { Participação dos gastos } \\
\text { públicos em saúde } \\
\text { ultrapassando } 50 \% \text { do total. } \\
\text { Ganho de escala nos } \\
\text { subsegmentos: hospitais, } \\
\text { laboratórios e operadoras. } \\
15 \% \text { dos hospitais (públicos } \\
\text { e privados) com mais de } 150 \\
\text { leitos em média (hoje são } \\
\text { apenas } 10 \% \text { ). } \\
\text { Parque de serviços de } \\
\text { diagnóstico e terapia com } \\
\text { menos de dez grandes } \\
\text { empresas dominando } 50 \% \text { do } \\
\text { mercado. } \\
\text { Número de operadoras de } \\
\text { planos e seguros inferior a mil } \\
\text { (hoje são cerca de } 1.700 \text { ). }\end{array}$ & $\begin{array}{l}\text { Aumento na capacidade } \\
\text { produtiva associado com } \\
\text { aumento na escala de } \\
\text { produção e diversificação de } \\
\text { serviços assistenciais. } \\
\text { Aumento da dependência } \\
\text { dos serviços de saúde do } \\
\text { financiamento público. } \\
\text { Participação de empresas } \\
\text { brasileiras prestadoras } \\
\text { de serviços de saúde } \\
\text { em empreendimentos } \\
\text { internacionais. } \\
\text { Primeiros empreendimentos } \\
\text { originários de investimentos } \\
\text { tipo PPP são reconhecidos } \\
\text { no segmento de prestadores } \\
\text { públicos de serviços saúde. } \\
\text { Grandes hospitais atraem } \\
\text { demanda de países latino- } \\
\text { americanos. } \\
\text { Diminuiçãa dos gargalos na } \\
\text { atenção médico-hospitalar } \\
\text { do SUS - ampliação } \\
\text { de cobertura, acesso, } \\
\text { universalização. } \\
\text { Fortalecimento da articulação } \\
\text { entre serviços e demais } \\
\text { subsegmentos para a } \\
\text { inovação. }\end{array}$ & $\begin{array}{l}\text { Expansão do PIB e geração de } \\
\text { emprego. } \\
\text { Estimativa de 2,5 milhões - } \\
\text { Programa Mais Saúde. } \\
\text { Aumento na dinâmica } \\
\text { econômica e maior sinergia } \\
\text { entre segmentos do CEIS. }\end{array}$ \\
\hline
\end{tabular}

CEIS - Complexo Econômico-Industrial da Saúde; PPP - Parceria Público-Privada; PIB - Produto Interno Bruto; SUS - Sistema Único de Saúde.

Fonte: elaboração própria. Referências: Política de Desenvolvimento Produtivo - PDP (Brasil. Ministério do Desenvolvimento, Indústria e Comércio Exterior, 2008), Programa Mais Saúde (Brasil. Ministério da Saúde, 2007) e PAC da Inovação (Brasil. Ministério da Ciência e Tecnologia e Inovação, 2007). 
Perspectivas a Longo Prazo: cenário desejável

O Subsistema de Serviços carrega o desafio da consolidação do efetivo sistema de proteção social, universal e público a longo prazo, sendo que, igualmente, representa importante fator de dinamismo econômico.

Duas grandes referências são balizadoras para se pensar um cenário ideal em que o país avança na universalização da saúde: o aumento dos gastos em saúde para $11 \%$ do PIB, representando, para além do próprio crescimento deste indicador, um incremento de recursos da ordem de 40\%; e, de modo associado, a duplicação dos recursos públicos no conjunto dos gastos em saúde, passando o financiamento público a ser responsável por algo como 70\% dos recursos para a saúde. Esse patamar significaria, em termos comparativos, o piso dos recursos públicos alocados para a saúde nos países da OCDE. Tal incremento permitiria que os gastos per capita em saúde crescessem substancialmente no período.

O aumento da parcela do financiamento público em saúde é condição para a efetiva consolidação do sistema público e universal. O modelo apresentado na Figura 6 corresponde a uma interdependência possível entre sistema público e universal, assegurado naturalmente pelo Estado, e o maior incentivo ao dinamismo econômico em saúde. O Estado, em sistemas de proteção social, como no caso brasileiro, precisa, segundo Viana e Elias (2007), desmercantilizar os acessos aos serviços e ao mesmo tempo, assumindo a saúde como bem econômico, promover uma interação com a oferta em bases mercantis. Essa transformação do modelo brasileiro corresponderia, a longo prazo, à resolução do desafio hoje estabelecido, qual seja, o de estender a cobertura, promovendo inclusão no sistema, portanto respondendo às demandas da vertente sociossanitária, ao mesmo tempo que a vertente econômica é dinamizada, assumindo-se novos padrões de sinergia entre estas duas dimensões.

Figura 6 - Princípios para um sistema de saúde com proteção social do Estado e incentivo à dinâmica econômica

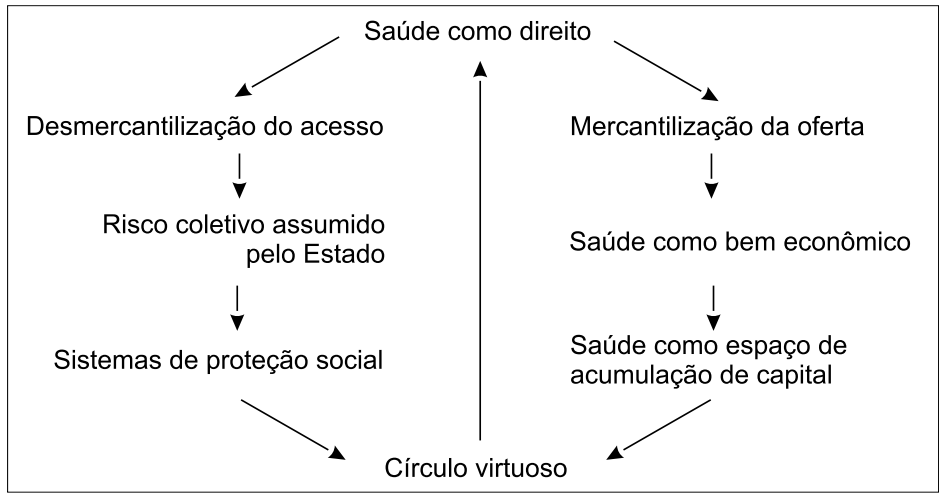

Fonte: adaptado de Viana \& Elias, 2007. 
A estrutura de serviços tem sido bastante reformulada, com alguns destaques em termos estruturais. Os hospitais devem apresentar escopos redefinidos, concentrando recursos cruciais para a alta complexidade e atenção prioritária à agudização de situações crônicas, observadas nítidas tendências demográficas e epidemiológicas. Em termos de escala, é necessário dobrar o número médio de leitos, de modo a se alcançar o patamar de 120 leitos por hospital, com aumento de 100\% em relação aos dados de 2005.

A concepção de redes integradas de serviços, com lógicas de integração vertical e também horizontal, prioridade na reformulação do sistema nacional de saúde na atualidade, deve contribuir para melhorar a operacionalização dos sistemas, internamente diferenciados segundo tecnologias e demandas específicas, mantendo elevada integração e racionalidade na utilização e continuidade de cuidados. Novas unidades assistenciais deverão continuar compondo as redes de atenção, incluindo ampliação de hospitais-dia, abertura de serviços específicos para cuidados de idosos, cuidados de enfermagem e cuidados paliativos, além de importante expansão da atenção domiciliar e ênfase em cuidados remotos mediante popularização do uso de Tecnologias de Informação e Comunicação (TICs) em saúde.

Todo o incremento tecnológico extra-hospitalar, combinado com alteração no escopo dos hospitais, mediante concentração de atividades intensivas em tecnologia, clínica e cirúrgica, promoverá importante movimento por desospitalização, já presente nos dias de hoje, mas que tenderá a ser ainda mais forte, acarretando significativa diminuição da relação leitos por habitantes, que em 2009 era de 2,26 leitos por mil habitantes, para padrões inferiores a 1,5 leito para cada mil habitantes (IBGE, 2010c).

A Figura 7 sintetiza o modelo integrado de serviços de saúde, considerando sua diferenciação e sua integração em rede.

Figura 7 - Sistemas com maior diferenciação de serviços: configuração de redes integradas de atenção

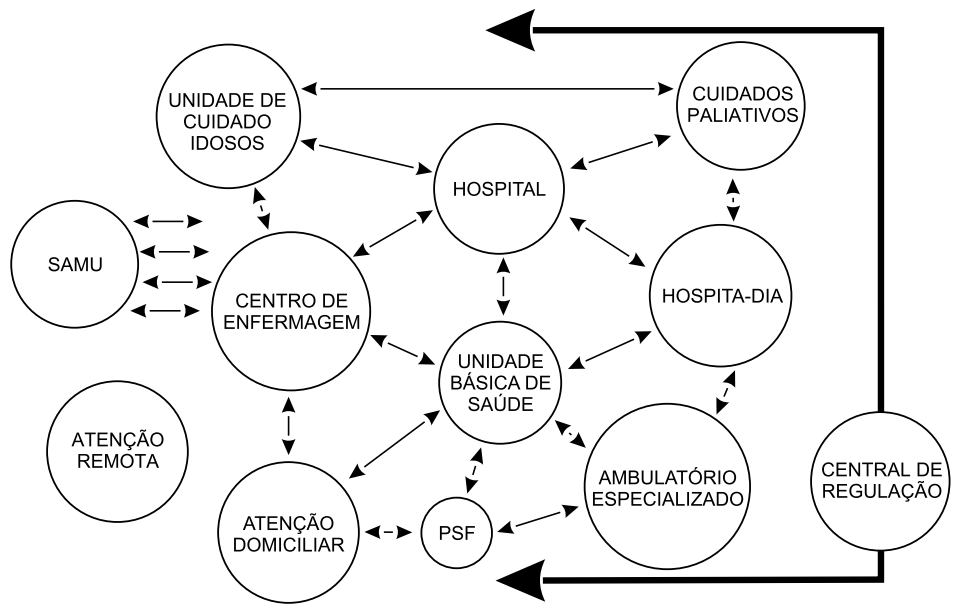

Fonte: adaptado de Mendes, 2001. 
Esse modelo tem como pilar essencial as TICs associadas a verdadeiras redes de inovação em saúde que articulam os serviços com as indústrias, os médicos e os pesquisadores. Estima-se que cerca de $60 \%$ das atividades nos serviços de saúde envolvam troca de informações passíveis de automação (Gallouj, 2002). Não são poucos os exemplos de atividades dos serviços que já encerram intensa carga de automação, em equipamentos biomédicos mas também em serviços, a destacar possibilidades reais e já regulamentadas legalmente para todo o manuseio de documentações médicas. o futuro não apenas do hospital, mas do conjunto dos serviços, envolvendo diagnóstico, monitoramento e mesmo terapias (inclusive cirúrgicas) remotas com base em TICs já é em parte uma realidade e sobretudo uma tendência inexorável. Hoje, alguns poucos hospitais de ponta no país desenvolvem projetos para eliminar todos os registros que não estejam automatizados, cunhando o termo 'hospital sem papel'. Há hospitais em que essa realidade será alcançada em mais dois ou três anos. A Figura 8 apresenta diversas possibilidades para uso das TICs, possibilitando importante racionalidade sistêmica e ganhos técnicos, de qualidade e de custos.

Figura 8 - Novas TICs e inovações em serviços de saúde

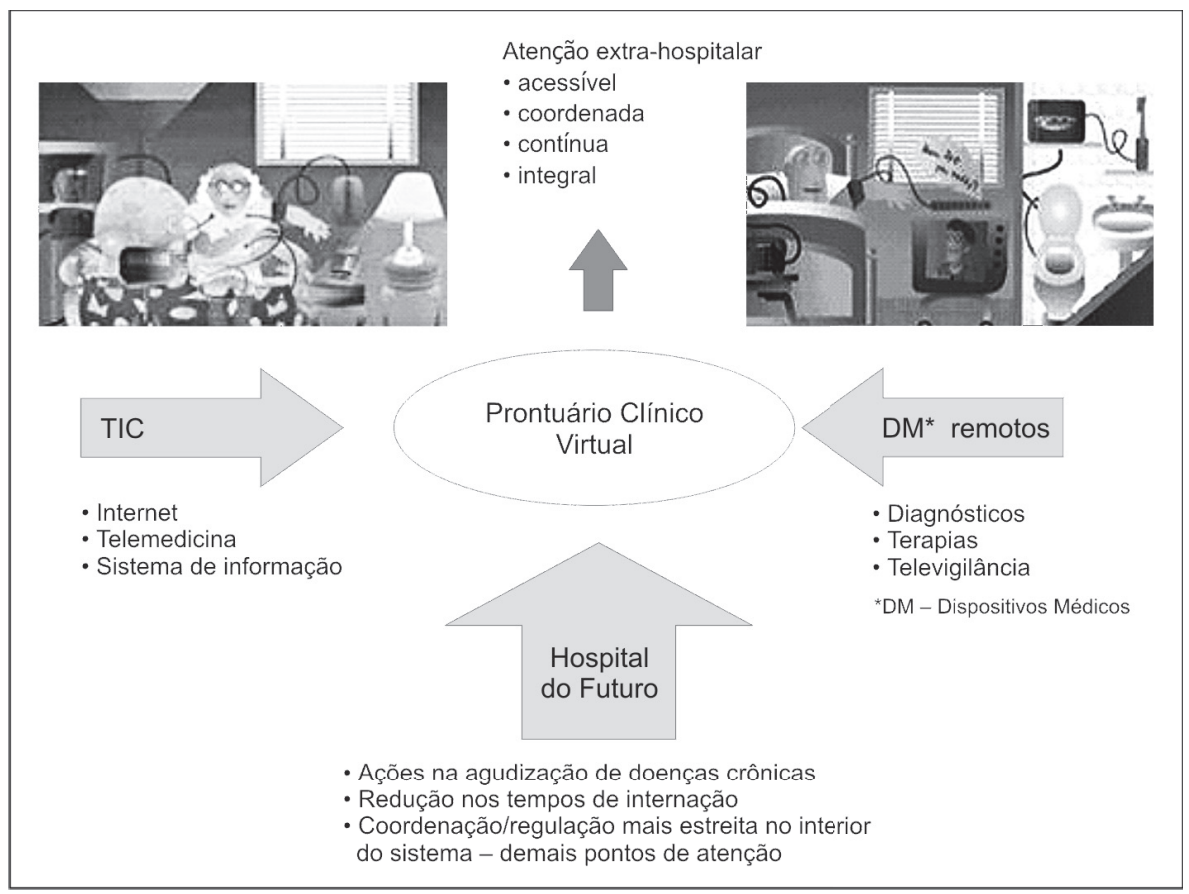

Fonte: elaborado por GIS/Ensp-VPPIS/Fiocruz, 2008.

O mercado privado, por sua vez, deverá estar em grande parte subordinado e integrado ao sistema público. Espera-se um processo de integração, tanto vertical 
quanto horizontal, constituindo-se redes com vários e diferenciados equipamentos de atenção. No cenário esperado, com expansão de cobertura do sistema público, o setor privado assume tanto a condição de prestador de serviços do sistema como a lógica de sistema suplementar, por meio das operadoras de planos e seguros, permitindo alternativas na forma do modelo inglês ou canadense, que propiciem escolhas fora do sistema público. Estima-se que o mercado de operadoras sofrerá importante concentração e mesmo redução da população coberta, tomando-se o contexto desejado como referência.

No interior dos serviços, as estratégias de inovação deverão consolidar importantes tecnologias que hoje se encontram, em grande parte, em fase de pesquisa e ainda dando os primeiros passos em desenvolvimento, entre as quais se destacam as terapias genéticas, diversas aplicações médicas da nanotecnologia e o uso de novos materiais e biomateriais.

Ao longo dos anos serão cada vez mais intensos os processos de inovação gerados por associações entre serviços e os demais segmentos do complexo, com importância crescente dos serviços como plataforma para a inovação, em função de suas capacidades dinâmicas e de novas estratégias e incentivos em Pesquisa e Desenvolvimento (P\&D), mediante redes e arranjos para a inovação em saúde. Especialmente hospitais de maior complexidade, como os institutos e os universitários, assumirão posições angulares no processo de $P \& D$ em saúde, incluindo papéis específicos no sistema regulador das incorporações tecnológicas no sistema.

O Quadro 13 sintetiza o cenário desejável a longo prazo, indicando os determinantes da dinâmica dos investimentos, as metas para 2022, os impactos no Subsistema de Serviços e os efeitos esperados no conjunto da economia.

Quadro 13 - Perspectivas a longo prazo. Cenário desejável - 2022

\begin{tabular}{|c|c|c|c|}
\hline $\begin{array}{l}\text { DETERMINANTES DA DINÂMICA } \\
\text { DO INVESTIMENTO ESPERADO }\end{array}$ & METAS PARA 2022 & $\begin{array}{l}\text { IMPACTOS NO SUBSISTEMA DE } \\
\text { SERVIÇOS }\end{array}$ & $\begin{array}{l}\text { EFEITOS ESPERADOS NO } \\
\text { CONJUNTO DA ECONOMIA }\end{array}$ \\
\hline $\begin{array}{l}\text { Expansão da participação } \\
\text { pública nos gastos em } \\
\text { serviços de saúde. } \\
\text { Estímulo a modalidades de } \\
\text { investimentos no sistema } \\
\text { público com base na } \\
\text { iniciativa privada (p. ex., } \\
\text { parcerias público-privadas). } \\
\text { Estímulo a associações e } \\
\text { formação de conglomerados } \\
\text { de serviços gerando } \\
\text { economias de escala. }\end{array}$ & $\begin{array}{l}\text { Aumento nos gastos públicos } \\
\text { em saúde para } 7 \% \text { do PIB. } \\
\text { Saúde alcançando } 11 \% \\
\text { do PIB. } \\
\text { Participação dos gastos } \\
\text { públicos em saúde elevando- } \\
\text { se a } 70 \% \text { do total. }\end{array}$ & $\begin{array}{l}\text { Aumento na capacidade } \\
\text { produtiva associada com } \\
\text { aumento na escala de } \\
\text { produção e diversificação de } \\
\text { serviços assistenciais. } \\
\text { Aumento da dependência } \\
\text { dos serviços de saúde do } \\
\text { financiamento público. } \\
\text { Participação de empresas } \\
\text { brasileiras prestadoras } \\
\text { de serviços de saúde } \\
\text { em empreendimentos } \\
\text { internacionais. }\end{array}$ & $\begin{array}{l}\text { Expansão do PIB e geração } \\
\text { de emprego (cerca de } 10 \\
\text { milhões). } \\
\text { Modernização da capacidade } \\
\text { produtiva e aumento da } \\
\text { produtividade. } \\
\text { Maior sinergia entre o } \\
\text { segmento Serviços e demais } \\
\text { segmentos do CEIS. } \\
\text { Consolidação do CEIS como } \\
\text { área de alto dinamismo na } \\
\text { estrutura produtiva brasileira. }\end{array}$ \\
\hline
\end{tabular}


Quadro 13 - Perspectivas a longo prazo. Cenário desejável - 2022 (continuação)

\begin{tabular}{|c|c|c|c|}
\hline $\begin{array}{l}\text { DETERMINANTES DA DINÂMICA } \\
\text { DO INVESTIMENTO ESPERADO }\end{array}$ & METAS PARA 2022 & $\begin{array}{l}\text { IMPACTOS NO SUBSISTEMA DE } \\
\text { SERVIÇOS }\end{array}$ & $\begin{array}{l}\text { EFEITOS ESPERADOS NO } \\
\text { CONJUNTO DA ECONOMIA }\end{array}$ \\
\hline $\begin{array}{l}\text { Ampliação do uso de } \\
\text { tecnologias mais intensivas } \\
\text { no âmbito dos serviços - } \\
\text { equipamentos e NTICs. } \\
\text { Incremento na complexidade } \\
\text { de leitos hospitalares. } \\
\text { Deslocamento de atividades } \\
\text { menos complexas para outros } \\
\text { tipos de serviços - postos de } \\
\text { saúde, ambulatórios, serviços } \\
\text { de home care, serviços } \\
\text { móveis pré-hospitalares. } \\
\text { Incorporação de novas } \\
\text { tecnologias e ampliação } \\
\text { nas modalidades } \\
\text { assistenciais (cuidados } \\
\text { para idosos, cuidados de } \\
\text { enfermagem, home care etc.) } \\
\text { acompanhando tendências } \\
\text { epidemiológicas e novas } \\
\text { possibilidades tecnológicas } \\
\text { (NTICs, telemedicina, } \\
\text { nanotecnologia). } \\
\text { Adequação do arcabouço de } \\
\text { gestão pública gerando mais } \\
\text { eficiência no gasto e relações } \\
\text { mais dinâmicas envolvendo } \\
\text { o setor privado prestador de } \\
\text { serviços. } \\
\text { Estrutura de serviços } \\
\text { mais competitiva e } \\
\text { internacionalizada. }\end{array}$ & $\begin{array}{l}\text { Estruturação de parque } \\
\text { hospitalar dobrando- } \\
\text { se o número médio } \\
\text { de leitos atualmente } \\
\text { existente e adensando-0 } \\
\text { tecnologicamente, de forma a } \\
\text { que se alcancem } 120 \text { leitos/ } \\
\text { hospital. } \\
\text { Parque de serviços de } \\
\text { diagnóstico e terapia } \\
\text { composto por grandes } \\
\text { empresas com elevado } \\
\text { padrão tecnológico. } \\
\text { Número de operadoras de } \\
\text { planos e seguros reduzido. } \\
\text { Universalização do acesso e } \\
\text { estrutura produtiva dinâmica. }\end{array}$ & $\begin{array}{l}\text { Consolidação de grupos } \\
\text { empresariais com e sem fins } \\
\text { lucrativos como importantes } \\
\text { players no segmento } \\
\text { de serviços de saúde } \\
\text { (hospitalares, serviços de } \\
\text { diagnóstico e operadoras de } \\
\text { seguros e planos). } \\
\text { Consolidação do Brasil como } \\
\text { principal polo de serviços de } \\
\text { saúde na América Latina. } \\
\text { Fortalecimento do SuS, } \\
\text { com legitimidade nacional e } \\
\text { reconhecimento internacional, } \\
\text { por sua eficiência e eficácia, } \\
\text { como modelo de política } \\
\text { pública e geração de } \\
\text { dinâmica econômica. }\end{array}$ & $\begin{array}{l}\text { Aumento do dispêndio } \\
\text { em P\&D e com atividades } \\
\text { inovativas no setor privado. } \\
\text { Fortalecimento da capacidade } \\
\text { e qualidade de trabalho da } \\
\text { população economicamente } \\
\text { ativa. }\end{array}$ \\
\hline
\end{tabular}

CEIS - Complexo Econômico-Industrial da Saúde; NTICs - Novas Tecnologias de Informação e Comunicação; P\&D - Pesquisa e Desenvolvimento; PIB - Produto Interno Bruto; SUS - Sistema Único de Saúde.

Fonte: elaboração própria.

\section{PROPOSIÇÃO DE POLÍTICAS}

A consolidação do modelo de proteção social na saúde, conforme proposição para o cenário a longo prazo, impõe aumento sistemático dos gastos públicos, invertendose a relação entre gasto público e gasto privado para novos padrões. O desejável é que se alcancem médias hoje já praticadas em sistemas com tais propósitos, ou seja, que pelo menos $70 \%$ dos gastos em saúde tenham financiamento público. 
A coordenação do sistema de saúde público, o SUS, pelo Estado exige novos mecanismos de pactuação e regulação entre entidades estaduais e municipais, que, visando a adequadas escalas e escopos de serviços no plano regional, estabeleçam lógicas típicas de arranjos produtivos sustentáveis, incluindo naturalmente racionalização e integração entre papéis dos estados e municípios. Tais arranjos supõem um grau de resolutividade importante, mantendo-se lógicas de referenciamento para tratamentos mais diferenciados e concentrados em polos mais centrais. Os arranjos regionais, intramunicipais para os municípios de grande porte, municipais e mesmo intermunicipais devem estar instituídos e ser assumidos como base de todo o sistema nacional. Será preciso que os sistemas estejam interligados e propiciando as mais diversas interações, naturalmente com base intensiva em TI. Nesse sentido devese conferir grande prioridade para os incentivos aos programas específicos para o desenvolvimento de TICs aplicadas à saúde.

O intenso processo de inovação exigirá adequadas políticas de incorporação tecnológica e demandará capacidade regulatória do Estado, visando às ajustadas opções tecnológicas em bases de custo-benefício comprovadas. Opções tipo agência, articulando institutos científicos e de pesquisa, deverão compor sistemas de monitoramento e avaliação tecnológica em saúde, integrando ainda hospitais acadêmica e tecnologicamente diferenciados.

No campo do investimento público, novos modelos deverão ser implementados, tais como as PPPs, hoje absolutamente incipientes em saúde. Essa lógica de investimento é bastante aderente a propósitos de dinamização do mercado privado de modo associado à responsabilidade do Estado pelos serviços. Seja por meio de PPPs ou mesmo de investimentos diretos, impõe-se uma recuperação sem igual na rede prestadora de serviços, especialmente hospitalar. Deverão ser estabelecidos programas para fechamento e/ou transformação de hospitais fora de escopo e escala, combinando com estratégias para fusões e associações, tanto entre unidades públicas quanto privadas, visando à maior racionalidade e sustentabilidade econômica do sistema, ao mesmo tempo que novos padrões de segurança e qualidade para profissionais e clientes sejam estabelecidos. Essa política deve perseguir o objetivo de dobrar o número médio de leitos hospitalares no país, e estes deverão incorporar diferenciada complexidade tecnológica, à altura dos padrões de demanda das unidades hospitalares. A abertura de novos hospitais públicos ou privados deverá respeitar, além de elementos de escala e escopo, padrões de inserção na rede de serviços, com base em planejamento sanitário regulado pelo poder público.

A diferenciação do sistema exige ainda o fomento à abertura de novos tipos de serviços, tais como unidades de cuidados de enfermagem, cuidados para idosos, cuidados paliativos, unidades para diagnóstico e tratamentos tipo hospital-dia. Empresas e serviços para monitoramento e tratamento remotos, basicamente domiciliares, 
deverão mobilizar importantes tecnologias, tanto biomédicas quanto baseadas em informação e comunicação, permitindo integrações a centros de regulação e controle, internos a hospitais e a outros serviços médicos e de enfermagem.

Novos modelos e sistemas de gestão, tanto para os serviços públicos quanto para os privados, devem ser desenvolvidos. A base autonomista nos serviços públicos deve ser alcançada mediante nítida separação, no interior do Estado, entre as funções de formulação de políticas, financiamento e regulação e a prestação de serviços propriamente dita. As lógicas atuais relacionadas com contratualização deverão estar bem mais disseminadas e propiciar adequada coordenação entre as unidades de governo, gestoras dos sistemas e os respectivos prestadores de serviços.

Todo esse processo de inovação no campo da gestão parte do reconhecimento da enorme defasagem entre os instrumentos e práticas gerenciais em saúde e contextos mais eficientes e eficazes, tanto no âmbito da gestão de sistemas quanto no de unidades, sobretudo hospitalares, dada sua particular complexidade. No âmbito do Estado, não há como continuar buscando eficiência e qualidade sem que ajustes legais administrativos sejam promovidos, considerando-se que as unidades de serviços constituem, de fato, grandes unidades empresariais que requerem novas formas de organização favoráveis à inovação. A administração pública não está à altura dos atuais desafios do sistema de saúde, e o não enfrentamento dessa deficiência compromete sobremaneira o seu futuro, em especial diante das exigências mais complexas que se anunciam, incluindo todo o sistema de relacionamento, competição cooperativa e regulação do setor privado de serviços. As práticas de inovação na gestão necessitam, portanto, de ações já a curto prazo, mas que sejam também medidas permanentes, capazes de continuadamente apoiar e induzir inovações em gestão.

o papel do Estado como formulador e indutor de programas de atenção e de inovações no âmbito de um sistema nacional de inovação em saúde requer que instituições públicas diferenciadas sejam fortalecidas e desempenhem papéis angulares em todo o sistema. Especialmente lógicas de cooperação do tipo PPP propiciarão maior dinamismo no processo de inovação no complexo. Instituições como a Fiocruz, os atuais institutos do Ministério da Saúde - Instituto Nacional do Câncer, Instituto Nacional de Traumatologia e Ortopedia, Instituto Nacional de Cardiologia -, além de alguns hospitais universitários específicos, devem ocupar espaços estratégicos no interior do sistema, em função de acúmulos científicos e de pesquisa e desenvolvimento de novas tecnologias, ao mesmo tempo que estejam inseridos no mercado prestador, gerando sinergias tanto no âmbito das indústrias do complexo quanto entre prestadores de serviços.

O Quadro 14 sintetiza as proposições de política para o Subsistema de Serviços, articulando os investimentos induzidos e estratégicos com os instrumentos relacionados a incentivos, regulação e coordenação. 


\section{Quadro 14 - Proposição de políticas. Síntese}

\begin{tabular}{|c|c|c|c|c|}
\hline \multicolumn{5}{|c|}{ TIPOS DE INSTRUMENTO } \\
\hline \multirow{3}{*}{ 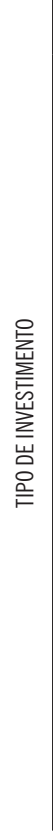 } & \multirow{3}{*}{ INDUZIDO } & INCENTIVOS & REGULAÇÃO & COORDENAÇÃO \\
\hline & & $\begin{array}{l}\text { Ampliar gastos públicos } \\
\text { em saúde para viabilizar a } \\
\text { expansão dos serviços visando à } \\
\text { universalização, à equidade e à } \\
\text { integralidade. } \\
\text { Financiar os investimentos dos } \\
\text { programas nacionais de saúde: } \\
\text { Mais Saúde (PAC) e outros. } \\
\text { Promover incentivos financeiros } \\
\text { e fiscais para a expansão da } \\
\text { capacidade produtiva e para } \\
\text { a introdução de inovações } \\
\text { incrementais. } \\
\text { Criar mecanismos de incentivo } \\
\text { para a indução da eficiência } \\
\text { nos serviços públicos } \\
\text { (contratualização, novos } \\
\text { modelos de gestão etc.). }\end{array}$ & $\begin{array}{l}\text { Ajuste no marco regulatório } \\
\text { do SUS: estabelecimento } \\
\text { de novas modalidades de } \\
\text { contratação de serviços públicos } \\
\text { e transformação dos modelos } \\
\text { de gestão dos serviços públicos, } \\
\text { induzindo mais eficiência, } \\
\text { autonomia e cultura de } \\
\text { resultados. } \\
\text { Aprimoramento na regulação } \\
\text { da ANS sobre as operadoras e } \\
\text { na sua relação com os serviços } \\
\text { privados para estimular } \\
\text { estruturas empresariais com } \\
\text { escala produtiva e qualidade } \\
\text { adequadas e indutoras de } \\
\text { inovações custo-efetivas. } \\
\text { Reestruturar a regulação da } \\
\text { incorporação tecnológica pelo } \\
\text { SUS para estimular a introdução } \\
\text { de inovações custo-efetivas. }\end{array}$ & $\begin{array}{l}\text { Articular os organismos, } \\
\text { políticas, programas e ações } \\
\text { assistenciais com o fortalecimento } \\
\text { da capacidade produtiva e de } \\
\text { inovação incremental da base } \\
\text { produtiva de serviços e industrial. } \\
\text { Iniciar um processo de articulação } \\
\text { dos serviços do sistema produtivo } \\
\text { da saúde com as estruturas de } \\
\text { governança da PDP e do Gecis } \\
\text { em particular, envolvendo os } \\
\text { ministérios da Saúde, da Ciência } \\
\text { e Tecnologia e Inovação e do } \\
\text { Desenvolvimento, da Indústria e do } \\
\text { Comércio Exterior. }\end{array}$ \\
\hline & & & & \\
\hline
\end{tabular}


Quadro 14 - Proposição de políticas. Síntese (continuação)

\begin{tabular}{|c|c|c|c|c|}
\hline \multicolumn{5}{|c|}{ TIPOS DE INSTRUMENTO } \\
\hline & & INCENTIVOS & REGULAÇÃO & COORDENAÇÃO \\
\hline 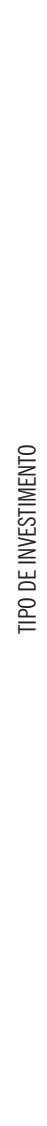 & ESTRATÉGICO & $\begin{array}{l}\text { Definir um novo arranjo do } \\
\text { financiamento à saúde para } \\
\text { viabilizar a transformação } \\
\text { e regionalização da rede de } \\
\text { serviços (saúde respondendo por } \\
11 \% \text { do PIB, com aumento da } \\
\text { participação pública para 70\% } \\
\text { do total). } \\
\text { Introduzir novos mecanismos e } \\
\text { incentivos financeiros e fiscais } \\
\text { para viabilizar a retomada } \\
\text { estrutural dos investimentos } \\
\text { públicos e privados em serviços } \\
\text { de saúde (desoneração tributária } \\
\text { do investimento estratégico, } \\
\text { parcerias público-privadas etc.). } \\
\text { Induzir formação de grandes } \\
\text { grupos públicos e privados } \\
\text { de prestadores de serviços, } \\
\text { aumentando a escala e a } \\
\text { estrutura de governança para } \\
\text { viabilizar a inovação e o acesso. } \\
\text { Introduzir mecanismos que } \\
\text { articulem o financiamento do } \\
\text { investimento em serviços com } \\
\text { processos de inovação nos } \\
\text { demais subsistemas do CEIS, } \\
\text { permitindo a adoção de novas } \\
\text { modalidades de serviços (uso } \\
\text { intensivo de tecnologia de } \\
\text { informação, atenção domiciliar } \\
\text { etc.). }\end{array}$ & $\begin{array}{l}\text { Transformação no marco } \\
\text { regulatório do SUS para } \\
\text { estimular novos modelos de } \\
\text { parcerias entre o setor público } \\
\text { e o privado; modelos de gestão } \\
\text { inovadores; e a articulação } \\
\text { estratégica dos serviços com os } \\
\text { segmentos industriais (arranjos } \\
\text { produtivos regionalizados, } \\
\text { dinâmicos e indutores do } \\
\text { acesso). } \\
\text { Adequar a regulação da } \\
\text { incorporação tecnológica nos } \\
\text { âmbitos público e privado } \\
\text { para estimular inovações } \\
\text { que ampliem o acesso, a } \\
\text { regionalização e novas formas } \\
\text { de atenção. }\end{array}$ & $\begin{array}{l}\text { Incorporação definitiva dos } \\
\text { serviços nas políticas para o } \\
\text { CEIS para viabilizar o tratamento } \\
\text { sistêmico, a produção e a inovação } \\
\text { incremental e radical em saúde. } \\
\text { Incorporação dos serviços em } \\
\text { todas as prioridades para o } \\
\text { desenvolvimento produtivo e a } \\
\text { inovação no CEIS dos ministérios e } \\
\text { agências de desenvolvimento. } \\
\text { Articulação do poder econômico } \\
\text { e de compra dos serviços com } \\
\text { o fortalecimento da capacidade } \\
\text { de produção e de inovação da } \\
\text { indústria. }\end{array}$ \\
\hline
\end{tabular}

ANS - Agência Nacional de Saúde Suplementar; CEIS - Complexo Econômico-Industrial da Saúde; Gecis - Grupo Executivo do Complexo Industrial da Saúde; PDP - Política de Desenvolvimento Produtivo; SUS - Sistema Único de Saúde.

Fonte: elaboração própria. 